\title{
Clostridium thermocellum as a Promising Source of Genetic Material for Designer Cellulosomes: An Overview
}

\author{
Dung Minh Ha-Tran ${ }^{1,2,3} \mathbb{D}$, Trinh Thi My Nguyen ${ }^{2}$ and Chieh-Chen Huang ${ }^{2,4, *, t}$ \\ 1 Molecular and Biological Agricultural Sciences Program, Taiwan International Graduate Program, \\ Academia Sinica and National Chung Hsing University, Taipei 11529, Taiwan; hatranminhdung@gmail.com \\ 2 Department of Life Sciences, National Chung Hsing University, Taichung 40227, Taiwan; \\ mytrinhnguyen0410@gmail.com \\ 3 Graduate Institute of Biotechnology, National Chung Hsing University, Taichung 40227, Taiwan \\ 4 Innovation and Development Center of Sustainable Agriculture, National Chung Hsing University, \\ Taichung 40227, Taiwan \\ * Correspondence: cchuang@dragon.nchu.edu.tw \\ † Mailing address: Life Sciences Building 4F. R.403, No. 145, Xingda Rd., Taichung 402, Taiwan.
}

Citation: Ha-Tran, D.M.;

Nguyen, T.T.M.; Huang, C.-C.

Clostridium thermocellum as a

Promising Source of Genetic

Material for Designer Cellulosomes:

An Overview. Catalysts 2021, 11, 996.

https://doi.org/10.3390/

catal11080996

Academic Editor: Giovanni Gadda

Received: 7 July 2021

Accepted: 18 August 2021

Published: 19 August 2021

Publisher's Note: MDPI stays neutral with regard to jurisdictional claims in published maps and institutional affiliations.

Copyright: (c) 2021 by the authors. Licensee MDPI, Basel, Switzerland. This article is an open access article distributed under the terms and conditions of the Creative Commons Attribution (CC BY) license (https:// creativecommons.org/licenses/by/ $4.0 /)$

\begin{abstract}
Plant biomass-based biofuels have gradually substituted for conventional energy sources thanks to their obvious advantages, such as renewability, huge quantity, wide availability, economic feasibility, and sustainability. However, to make use of the large amount of carbon sources stored in the plant cell wall, robust cellulolytic microorganisms are highly demanded to efficiently disintegrate the recalcitrant intertwined cellulose fibers to release fermentable sugars for microbial conversion. The Gram-positive, thermophilic, cellulolytic bacterium Clostridium thermocellum possesses a cellulolytic multienzyme complex termed the cellulosome, which has been widely considered to be nature's finest cellulolytic machinery, fascinating scientists as an auspicious source of saccharolytic enzymes for biomass-based biofuel production. Owing to the supra-modular characteristics of the $C$. thermocellum cellulosome architecture, the cellulosomal components, including cohesin, dockerin, scaffoldin protein, and the plentiful cellulolytic and hemicellulolytic enzymes have been widely used for constructing artificial cellulosomes for basic studies and industrial applications. In addition, as the well-known microbial workhorses are naïve to biomass deconstruction, several research groups have sought to transform them from non-cellulolytic microbes into consolidated bioprocessing-enabling microbes. This review aims to update and discuss the current progress in these mentioned issues, point out their limitations, and suggest some future directions.
\end{abstract}

Keywords: Clostridium thermocellum; cellulase booster; artificial cellulosomes; designer cellulosomes; Kluyveromyces marxianus; laccases; LPMOs

\section{Introduction}

During evolution, cellulolytic microbes developed an extracellular multienzyme complex called the cellulosomes to boost the cellulose degradation rate at maximum levels [1]. Clostridium thermocellum, a Gram-positive, thermophilic anaerobic bacterium, exhibits an outstanding capability for degrading cellulolytic biomass to release fermentable sugars of different lengths by means of its powerful cellulosomes. Since the polysaccharide compositions in plant cell walls vary substantially in both quality and quantity [2], C. thermocellum needs to mediate the composition of saccharolytic enzymes in the cellulosome complex to cope with the complexity and recalcitrance of a specific cell wall [3]. More than 70 cellulolytic enzymes-borne type-I dockerin (DocI) are noncovalently assembled onto the primary non-catalytic protein, termed scaffoldin (Scaf) CipA, through a calcium-dependent high-affinity interaction (i.e., dissociation constant $\mathrm{K}_{\mathrm{D}}<10^{-11} \mathrm{M}$ ) with the nine type-I cohesin (CohI) domains located on the CipA structure [4]. In addition, the CipA protein also contains a type-II dockerin (DocII) domain at its C-terminal to mediate the attachment 
of the cellulosome complex to the bacterial cell surface [5]. Correspondingly, C. thermocellum possesses three types of surface-anchoring Scaf(s), namely SdbA, Orf2p, OlpB, which contain one, two, and seven type-II cohesins (CohII), respectively, responsible for the binding of the cellulosome complex to the cell surface through CohII-DocII interaction.

Inspired by the Lego-like architecture of the $C$. thermocellum cellulosome, various research groups have been seeking to construct designer cellulosomes (DCs) for basic and applied studies [6-8]. Although there are several conjugation techniques to design artificial cellulosomes [9], the present review mainly focuses on the CohI-DocI interaction-based artificial cellulosome construction. Furthermore, the related issues of this approach, such as enzymatic unit positions, types of enzymes, linkers between DocI and catalytic domain, and number of carbohydrate-binding modules (CBMs), are updated and discussed. Another strategy is to recombinantly produce a library of individual catalytic enzymes with diverse hydrolytic reaction modes and then formulate the specified enzymatic cocktails for specific substrates [10]. In addition, to convert non-cellulolytic biofuels-producing microbes into consolidated bioprocessing (CBP)-enabling microbes, which can conduct enzyme production, substrate saccharification, and fermentation of the released sugars into biofuels in a single step, various studies have been carried out to express heterologous cellulolytic enzymes in heterologous host cells to make them genetically engineered cellulolytic microbes [11]. These engineered microbes use a cell-surface display or secretion system to display their novel hydrolytic capability. These strategies, with strengths and weaknesses, are discussed in the present review.

\section{Reservoir of Recombinant Enzymes for In Vitro Reconstitution of Artificial Cellulosomes}

\subsection{Impact of Processive Endoglucanase Component in Designer Cellulosome on Biomass Decomposition}

In nature, an efficient decomposition of cellulosic biomass strongly depends on a fast adaptation of $C$. thermocellum to enable the regulation of its cellulosomal enzymes for a specific substrate composition. The prompt response of $C$. thermocellum is due to an elegant alternative sigma-anti sigma system [12] that quickly and flexibly regulates the expression of cellulosomal genes in its genome. As there are numerous cellulases with diverse functions, a comparative study on the hydrolytic activity profiles and product formation of $24 \mathrm{C}$. thermocellum cellulosomal cellulases was performed by Leis et al. (2017) [13]. The cellulases can be distinguished from each other based on the hydrolysis modes on Avicel and soluble sugars release. The first group comprising non-processive endoglucanases (EG), such as Cel8A, Cel5E, Cel5H, Cel9-44J, and Cel9T, released longchain polysaccharides with degree of polymerization (DP) $\geq 5$. This group was found to show the highest activity on CMC and barley $\beta$-glucan. The second group consists of exomode cellobiohydrolases (CBHs) (i.e., Cel48S, Cel9K, Cbh9A) with cellobiose as the only end-product during Avicel hydrolysis. The third group is comprised of all cellotetraosetype processive EGs (pEG4) family 9, namely Cel9F, Cel9N, Cel9P, Cel9Q, Cel9R, Cel9U, Cel9V, Cel9W, Lec9A, and Lec9B. All processive enzymes in this group, except for Cel9P that does not have a CBM3c, possess a GH9 catalytic module associated with a CBM3c. The last group includes processive cellobiose-type EGs (pEG2) such as Cel5B, Cel5G, Cel5L, Cel5O, and Cel9D. The Cel5O is the unique EG that has a CBM3b module in this group, while the other members only possess catalytic modules. The next step of this study was to form artificial mini-cellulosomes to determine synergistic effects between cellulase components. By doing so, the selected cellulases were allowed to bind to the recombinant scaffoldin protein CipA8 carrying 8 CohI subunits on its backbone structure. Regarding enzymatic assays in this study, all the enzyme assays were performed in a total volume of $0.5 \mathrm{~mL}$ at $60{ }^{\circ} \mathrm{C}$. The reaction buffer consisted of $0.1 \mathrm{M}$ MOPS, $\mathrm{pH}$ 6.5, $50 \mathrm{mM} \mathrm{NaCl}, 10 \mathrm{mM} \mathrm{CaCl}_{2}$, and $2 \mathrm{mM}$ Tris(2-carboxyethyl)phosphine (TCEP) functioning as a reducing agent. For the single cellulase assay, the barley $\beta$-glucan, CMC, PASC $(0.5 \%, w / v)$, or Avicel $(1 \%, w / v)$ were used. Avicel $(0.25 \%, w / v)$ was used for the determination of the complex cellulases activity with the standard enzyme load of $2 \mu \mathrm{g} / \mathrm{mL}$, 
while the 10-fold greater of Avicel concentration $(2.5 \%, w / v)$ was employed for enzyme kinetics assay. To eliminate the potential inhibition of cellobiose against the complexed cellulases, $6 \mu \mathrm{g} / \mathrm{mL}$ of $\beta$-glucosidase from Thermus thermophilus was used. Reducing sugars released from the substrates were measured using the 3,5-dinitrosalicylic acid (DNS) method and one enzymatic unit was defined as $1 \mu \mathrm{mol}$ of glucose equivalent released per minute. After $48 \mathrm{~h}$ of incubation on Avicel $(0.25 \%, w / v)$ at $60^{\circ} \mathrm{C}$, all divalent complexes, namely Cip8A:Cel48S/Cel9K, Cip8A:Cel9K/Cbh9A, and Cip8A:Cel48S/Cbh9A, with only $\mathrm{CBH}$ components bound to Cip8A, exhibited less hydrolysis efficiency. The combination of Cip8A:Cel48S/Ce19K/Cel5L (SKL) with Cel5L is a processive pEG2 enzyme, which yielded the maximum reducing sugars released $(737 \mu \mathrm{M} /$ reaction) among all trivalent minicellulosomal complexes. Interestingly, without pEG2 enzyme in its complex, the tetravalent cellulosome Cip8A:Cel48S/Cel9K/Cel8A/Cel9R (SKAR) showed lower activity compared to the SKL, which indicates the key role of the processive pEG2 enzyme in substrate decomposition. The nonavalent DC Cip8A:Cel48S/Cel9K/Cbh9A/Cel8A/Cel9Q/Cel9T/Cel5G/ Cel9R/Cel9-44J, which carried 9 enzymes of all 4 types of cellulases on its construct, reached approximately $52.6 \%$ of activity of the native $C t$ cellulosome (Figure 1 ).

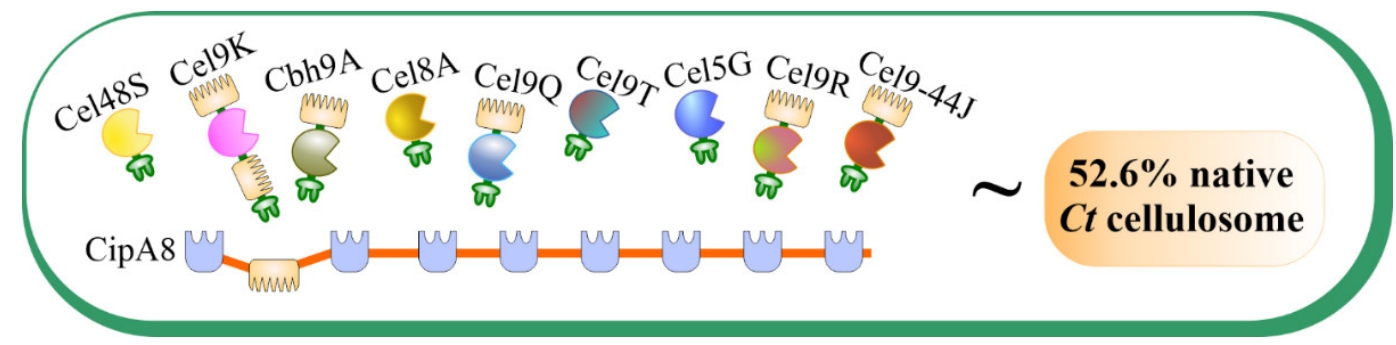

Figure 1. Full synthetic cellulosome complex containing 25\% of Cel48S, 12.5\% each of Cel9K, Cbh9A, Cel8A, Cel9Q, Cel9T, and 4.2\% each of Cel5G, Cel9R, and Cel9-44J (stoichiometric assembly ratio, $\% \mathrm{~mol}$ ), whereas the stoichiometric binding capacity equals 1:8 (CipA:single enzyme). Abbreviations in the Figure 1: Ct, C. thermocellum.

\subsection{Preparation of Recombinant C. thermocellum Cellulosomal Enzyme Library}

In terms of industrial cellulose degradation, a highly versatile pool of free single saccharolytic enzymes enables a faster adaptation to a given substrate while reducing the addition of unnecessary enzyme components. Based on this argument, Leis and coworkers [10] aimed to prepare a full recombinant cellulosomal enzyme reservoir in which all predicted 73 DocI-containing enzymes-encoding genes in the C. thermocellum DSM 1313 genome and the cip8A gene were cloned and expressed in E. coli DH10B and DH5 $\alpha$ cells. In total, 57 of the 73 DocI-bearing enzymes were successfully expressed and purified in a soluble form. An enzyme assay showed that the combination of two CBHs such as Cel48S and Cel9K and one EG Cel5L with the Scaf protein CipA8, namely CipA8:Cel48S/Cel9K/Cel5L complex (SKL), appeared to be sufficient for the hydrolysis of softwood pulp. However, the addition of a mannanase (Man26A) and a xylanase (Xyn10Y) to the SKL complex to form the SKLMY complex (i.e., CipA8:Cel48S/Cel9K/Cel5L/Man26A/Xyn10Y) dramatically increased the biomass degradation efficiency relative to the SKL. Enzyme assays were carried out at $60^{\circ} \mathrm{C}$ in $0.5 \mu \mathrm{L}$ of reaction buffer containing $0.1 \mathrm{M} \mathrm{MOPS}, \mathrm{pH} 6.5,50 \mathrm{mM} \mathrm{NaCl}$, $10 \mathrm{mM} \mathrm{CaCl}_{2}$. The activity of synthetic cellulosomes was measured using $0.25-0.5 \%(w / v)$ Avicel and $0.25 \%(w / v)$ micronized softwood pulp (UPM-Kymmene, Helsinki, Finland) as the substrates. The commercial Cellic Ctec2 (Novozymes, Sigma-Aldrich, St. Louis, $\mathrm{MO}$, USA) was incubated at $50^{\circ} \mathrm{C}$ in $0.1 \mathrm{M} \mathrm{MES}$ and $50 \mathrm{mM} \mathrm{CaCl}_{2}, \mathrm{pH} 5.0$. The enzyme $\beta$-glucosidase from $T$. thermophilus or Thermoanaerobacter brockii was supplemented to a final concentration of $6 \mu \mathrm{g} / \mathrm{mL}$ to avoid the inhibition of synthetic cellulosomes by cellobiose. After $48 \mathrm{~h}$ of incubation at $60-65^{\circ} \mathrm{C}$, the pentavalent SKLMY complex exhibited a higher thermostability, and displayed approximately $60 \%$ of enzyme activity relative to the commercial fungal enzyme mixture Cellic Ctec2. Moreover, the supplement of the 47 additional 
recombinant cellulosomal enzymes from the above-mentioned enzyme reservoir or of the SM901 native free cellulosomal enzyme with varying amounts into the SKLMY complex increased its activity to a level comparable with that of the commercial enzyme blend Cellic Ctec2 (Figure 2) (Note: The mutant C. thermocellum strain SM901 was devoid of cipA gene). As far as we know, this is the first report in which $78 \%$ of all putative $C$. thermocellum cellulosomal enzymes, in full length, were recombinantly produced in E. coli. In addition, a core enzyme complex with only five enzymes enabling an effective hydrolysis of Kraft pulp was determined.

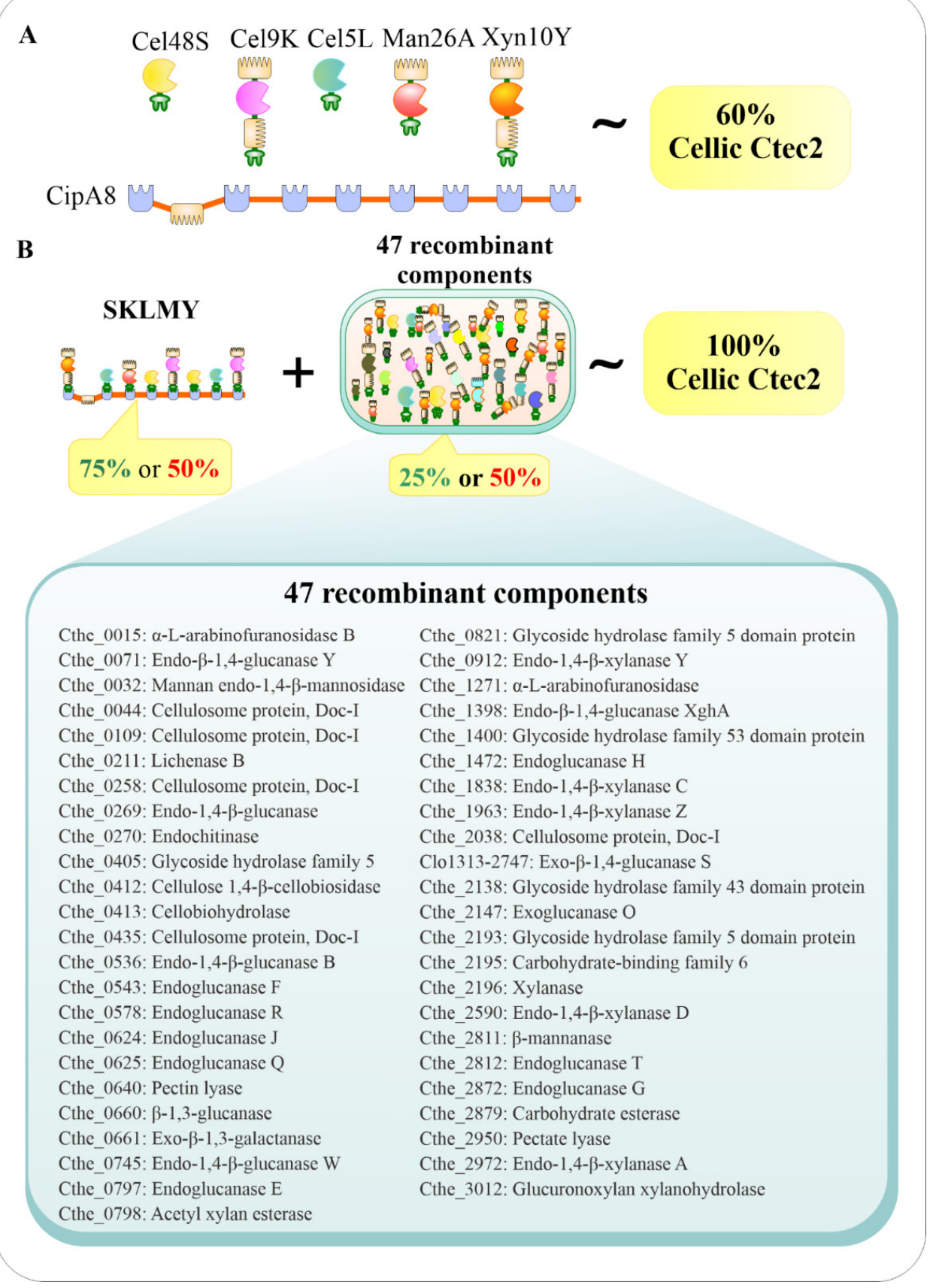

Figure 2. Construction of artificial cellulosome from a pool of recombinant cellulosomal enzymes from C. thermocellum. (A) The SKLMY complex with only 5 recombinant cellulosomal proteins exhibits $60 \%$ of catalytic efficiency as compared to the commercial Cellic Ctec 2 cocktail. (B) The mixture of SKLMY complex and 47 recombinant enzymes at different ratios expresses a comparative catalytic efficiency with the commercial Cellic Ctec2. 
Regarding the CohI-DocI binding flexibility, since there is no binding specificity between CohI and DocI originating from the same bacterium species $C$. thermocellum, an individual DocI-bearing catalytic component can theoretically randomly bind to any available CohI on the Scaf backbone architecture $[14,15]$. However, in the DCs constructed with divergent Coh-Doc pairs from different species, where the catalytic subunits were fused with divergent DocI with different specificities, the chimeric DocI is strictly required to bind to their corresponding CohI positioned on the chimeric Scaf [16]. The preparation of recombinant enzymes library from the same cellulolytic microbe, in our view, is an interesting and feasible strategy to quickly respond to the increasing interest in the search for a potent enzyme source in the cellulosic biofuel industry.

\section{Incorporation of Novel Enzymes into Artificial Cellulosomes}

\subsection{Integration of Laccase into Designer Cellulosomes}

Although C. thermocellum cellulosome is among the fastest and most efficient biocatalysts known for decomposing lignocellulosic biomass, the low yield of its fermentation products limits the application of this bacterium in biofuel production systems. A DC can be constructed by artificially self-assembling divergent chimeric protein complexes including CohI-bearing Scaf, DocI-bearing saccharolytic enzymes, and CBMs into a whole complex. By virtue of their supra-modular nature, the DCs enable the control of the number of enzymes, the composition, and position of these enzymes on a Scaf construct [17]. Previous studies showed that the synergy and proximity effects among enzymes in DCs promote an enhanced solubilization of inherent recalcitrant cellulosic biomass in comparison with their free enzyme counterparts [7].

Lignocellulose, the most abundant polymers complex on Earth, is composed of cellulose, hemicellulose, and lignin. The Cel48S enzyme is the most abundant enzymatic subunit in the isolated cellulosome of $C$. thermocellum $[3,18,19]$, and its important role in cellulose hydrolysis was obviously evidenced by Olson et al. [20] and Liu et al. [21]. Regarding catalytic components for DC construction, it is therefore not surprising that this cellobiohydrolase (CBH) family 48 was widely selected for constructing artificial cellulosomes and/or for preparing cellulase cocktails [10,13,22-24]. Similarly, the xylanase family $10 \mathrm{Xyn} 10 \mathrm{Z}$ responsible for xylan solubilization was frequently chosen for artificial cellulosomes [6,22]. The cellulase-xylanase synergy that facilitates the decomposition of complex substrates was noticed in previous studies [16,25-29]. In addition, the saccharolytic enzymes originated from the aerobic thermophilic bacterium Thermobifida fusca, with thermostability and potent catalytic efficiency [30], are identified as important starting materials for constructing DCs in several studies $[16,29,31-33]$.

While cellulose and hemicellulose are useful components to produce biofuels and other valuable biochemicals, lignin is often considered a barrier that needs to be removed during cellulosic substrate processing step. To this end, Davidi et al. [8] constructed a DocI-fused laccase Tfu1114 and incorporated it into a DC. Tfu1114 is a free monocopper polyphenol oxidase originated from the aerobic bacterium T. fusca, and it can remove some $\mathrm{C}-\mathrm{C}$ and/or $\mathrm{C}-\mathrm{O}$ bonds near to aromatic rings of lignin [34]. To overcome a challenge in the conversion of the free laccase Tfu1114 to the cellulosomal mode, a highly expressed GH10 xylanase (XynT6) from Geobacillus stearothermophilus was used as a solubility tag and fused at the $\mathrm{N}$-terminus of the Doc-containing laccase to generate XynT6-c-Lac. The XynT6 itself was fused with the Clostridium cellulolyticum Doc to form XynT6-c to promote xylan degradation. For cellulose conversion, the EG Cel5A and CBH Cel48A from T. fusca were fused with the Doc(s) from Ruminococcus flavefaciens (f) and C. thermocellum ( $\mathrm{t}$ ), respectively, to form the $\mathrm{f}-\mathrm{Cel} 5 \mathrm{~A}$ and $\mathrm{t}-\mathrm{Cel} 48 \mathrm{~A}$, respectively. In addition, the xylanase Xyn11V (Cthe_2972) from C. thermocellum ATCC 27405 was fused with an Acetivibrio cellulolyticus Doc (a) to form Xyn11V-a. To construct a backbone protein for the DC, a tetravalent ScafCATF with four diverse CohI(s) from C. cellulolyticum (C), A. cellulolyticus (A), C. thermocellum (T), and $R$. flavefaciens $(\mathrm{F})$, and a CBM3a from $C$. thermocellum was produced. The individual enzymes and the scaffoldin were incubated for $2 \mathrm{~h}$ at $37^{\circ} \mathrm{C}$ with $20 \mathrm{mM} \mathrm{CaCl}_{2}$ to facilitate 
cellulosome assembly. The resulting cellulosome complex $(0.5 \mu \mathrm{M})$ was examined for wheat straw decomposition in a 200- $\mu \mathrm{L}$ reaction buffer containing $50 \mathrm{mM}$ acetate buffer ( $\mathrm{pH} 5.0)$, $10 \mathrm{mM} \mathrm{CaCl}_{2}, 2 \mathrm{mM}$ EDTA, and $7 \mathrm{~g} / \mathrm{L}$ wheat straw. The reaction mixtures were incubated at $50{ }^{\circ} \mathrm{C}$ for $72 \mathrm{~h}$. As a result, the complexation of the tetravalent ScafCATF with all the four forms of DocI-bearing GHs, termed herein ScafCATF:XynT6-c-Lac/Xyn11V-a/tCel48A/f-Cel5A, displayed the highest saccharolytic activity, followed by the blend of four unbound enzymes $\mathrm{t}-\mathrm{Cel} 48 \mathrm{~A}, \mathrm{f}-\mathrm{Cel} 5 \mathrm{~A}, \mathrm{Xyn} 11 \mathrm{~V}-\mathrm{a}, \mathrm{XynT6}-\mathrm{c}$, and the mixture of $\mathrm{t}-\mathrm{Ce} 48 \mathrm{~A}$, f-Cel5A, Xyn11V-a, and XynT6-c-Lac. Without laccase, the complexations of ScafCATF:tCel48A/f-Cel5A/Xyn11V-a/XynT6-c and ScafCATF:t-Cel48A/f-Cel5A/Xyn11V-a could not maintain their robust activities toward wheat straw, thus indicating the key role of the laccase Tfu1114 in biomass hydrolysis.

\subsection{Incorporation of Lytic Polysaccharide Monooxygenases (LPMOs) into Designer Cellulosomes}

LPMOs, relatively new enzymes discovered one decade ago, are copper-dependent and play pivotal roles in the depolymerization of sugar-based biopolymers [35]. The low-molecular-weight lignin-derived compounds (LMWLDCs) released from biomass solubilization was found to be able to donate electrons to LPMOs for the oxidation of cell-wall polysaccharides [36]. The activities of LPMOs are copper-dependent and can only be induced in the presence of oxygen molecules and an electron donor, which can be delivered from enzyme GMC oxidoreductases, from lignin, phenolic compounds and from light-activated photosynthetic pigments. Insoluble high-molecular-weight lignin functions as a source of electrons, while the LMWLDCs transfer electrons to LPMOs and being oxidized. The LMWLDCs will be reverted to reduced state by receiving electrons from the bulk lignin, thus enabling a new electron delivery [37]. In the study by Arfi et al. [33], the two free LPMOs, such as TfLPMO10A (hereafter termed E7) and TfLPMO10B (hereafter termed E8) from T. fusca, were converted to the cellulosomal mode by fusing to a DocA (a) from A. cellulotyticus (Figure 3). Two versions of E7 were constructed: the first version E7-a was formed with the DocA fused directly at the C-terminus of the catalytic domain AA10, and the second version E7-sk-a was generated with a 12-aa short linker (sk) between AA10 and C-terminal. Three versions of E8 included E8-a with the DocA placed at its C-terminus, $\mathrm{E} 8 \Delta$-a where the native CBM domain was altered by the DocA and E8 $\Delta \Delta$-a with the FnIII and the CBM were replaced by the DocA. The cellulolytic activity of E8-a was similar to that of the WT counterpart, while the two versions $\mathrm{E} 8 \Delta-\mathrm{a}$, and $\mathrm{E} 8 \Delta \Delta-\mathrm{a}$ were negatively affected due to the removal of CBM domain. The activity of E7-sk-a was even a bit higher than that of WT E7, whereas E7-a without linker exhibited a dramatically reduced activity. A trivalent ScafABT was constructed with three CohI(s) from A. cellulolyticus, B. cellulosolvens, and $C$. thermocellum, and one CBM3a from $C$. thermocellum. Additionally, the endoglucanase TfCel5A and exoglucanase TfCel48A were converted to the cellulosomal mode $\mathrm{t}-\mathrm{Cel} 5 \mathrm{~A}$ and b-Cel48A by replacing their CBMs with Doc(s) from C. thermocellum and B. cellulosolvens, respectively. Cellulase assays were performed by incubating the enzyme with $1 \%(w / v)$ Avicel at $50{ }^{\circ} \mathrm{C}$ for $72 \mathrm{~h}$ in $50 \mathrm{mM}$ acetate buffer (pH 5.9) and $2 \mathrm{mM}$ ascorbic acid. Enzyme concentrations were $1 \mu \mathrm{M}$ for the WT and chimeric LPMOs enzymes or $0.5 \mu \mathrm{M}$ for the DCs. The three LPMO(s)-bearing DC(s), namely ScafABT:E8 $\Delta-\mathrm{a} / \mathrm{b}-\mathrm{Cel} 48 \mathrm{~A} / \mathrm{t}-\mathrm{Cel} 5 \mathrm{~A}$, ScafABT:E8 $\Delta \Delta-\mathrm{a} / \mathrm{b}-\mathrm{Cel} 48 \mathrm{~A} / \mathrm{t}-\mathrm{Cel} 5 \mathrm{~A}$, and ScafABT:E7-sk-a/b-Cel48A/t-Cel5A showed the highest activity towards Avicel, suggesting the superiority of cellulosomal architecture over the free enzymes (i.e., enzymes proximity synergy, robust substrate targeting, and enzyme-enzyme synergistic effects). Based on the hydrolysis capability of DCs, it should be noted that the LPMOs function as a booster when incorporated with other cellulases in increasing saccharolytic efficiency rather than being the main cellulose-degrading enzymes. 


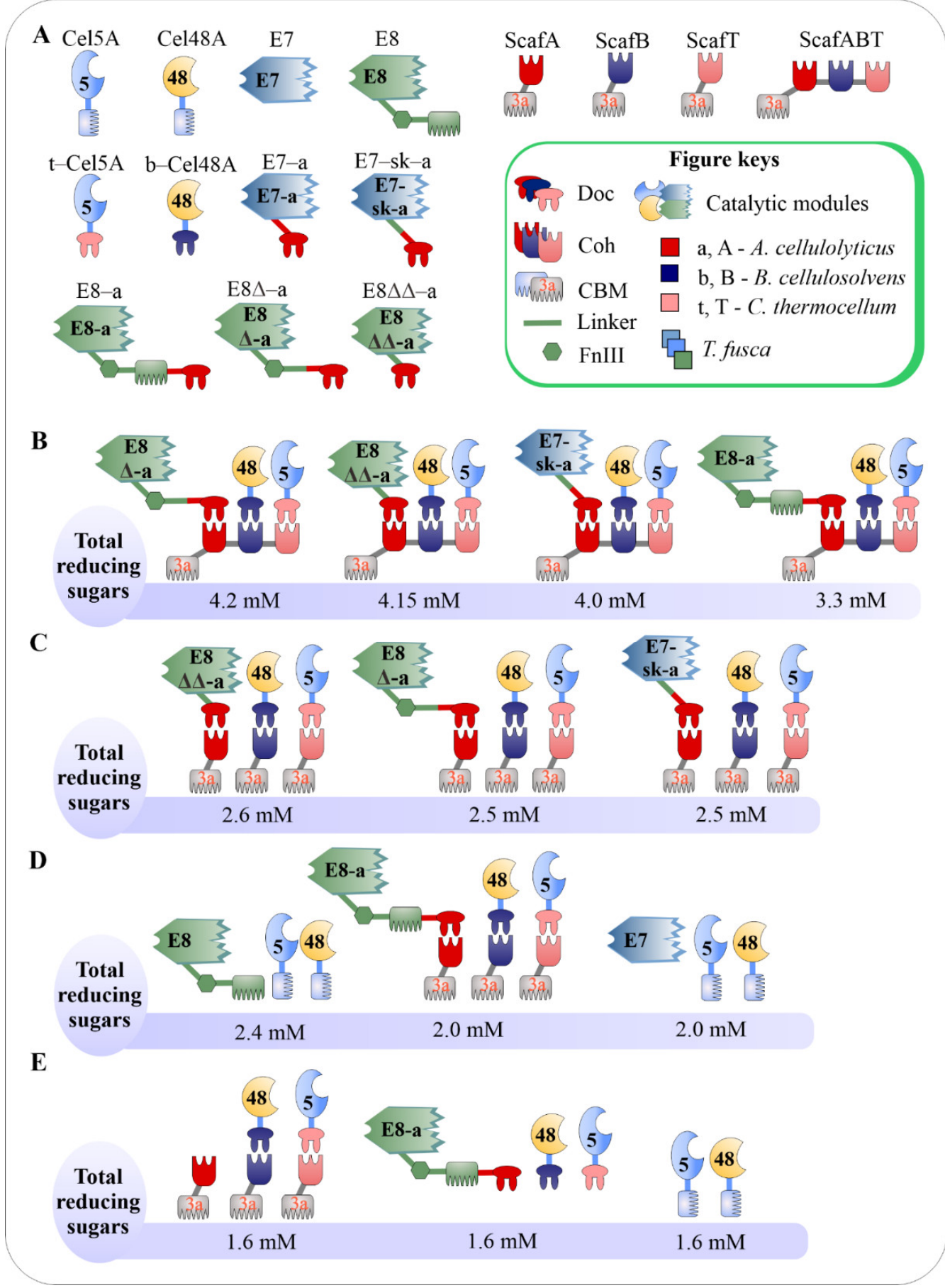

Figure 3. Hydrolysis of cellulose by LPMO-bearing DCs. (A) The WT form of Cel5A, Cel48A, E7, E8 and the converted enzyme variants $\mathrm{t}-\mathrm{Ce} 5 \mathrm{~A}, \mathrm{~b}-\mathrm{Cel} 48 \mathrm{~A}, \mathrm{E7}-\mathrm{a}, \mathrm{E} 7-\mathrm{sk}-\mathrm{a}, \mathrm{E} 8-\mathrm{a}, \mathrm{E} 8 \Delta-\mathrm{a}$, and E8 $\Delta \Delta-\mathrm{a}$. (B) The trivalent DCs with E7 and E8 variants exhibit the highest enzymatic activities. (C) The mixtures of chimeric individual enzymes also possess potent hydrolytic activities. (D) The mixtures of WT E8, E7, Cel5A, and Cel48A showed average activities. (E) Without LPMO in the enzyme mixtures, the capability of cellulose conversion was dramatically reduced.

\subsection{Incorporation of $\beta$-glucosidase into Designer Cellulosomes}

Previous studies noticed the inhibitory effect of glucose [38] and cellobiose [39,40] on cellulosomes. Therefore, eliminating this feedback inhibition enables an enhanced biomass conversion [41]. The activity of $\beta$-glucosidase BglA was found to be too low in WT C. thermocellum strains [42], and due to the adsorption of cellulosomes in cellulose 
matrix, only a small fraction of BglA is available to cellulosomes [43]. To address this problem, Gefen et al. (2012) [43] fused a $\beta$-glucosidase BglA protein with an unoccupied CohII and integrated this chimeric BglA-CohII complex into the purified C. thermocellum cellulosome. On Avicel and pretreated switchgrass, the cellulosomes, in combination with the resultant chimeric BglA-CohII complex, showed the highest saccharolytic efficiency, followed by the cellulosomes plus free WT BglA, and the $C$. thermocellum cellulosomes alone (Figure 4A). The enzyme activity was assayed in $50 \mathrm{mM}$ citrate buffer ( $\mathrm{pH} 6.0)$ and $15 \mathrm{mM}$ $\mathrm{CaCl}_{2}$ with $0.475 \mathrm{mg} / \mathrm{mL}$ cellulosome and $12.5 \%(w / v)$ Avicel or $4.2 \%(w / v)$ pretreated switchgrass as the substrate. The $\beta$-glucosidase concentration for the assay was $0.75 \mu \mathrm{M}$ for WT BglA or BglA-CohII in an equivalent specific activity. After the first reaction, the resultant supernatants were transferred into a new reaction mixture with $0.5 \mu \mathrm{M}$ WT BglA in $50 \mathrm{mM}$ citrate buffer ( $\mathrm{pH}$ 6.0) and $15 \mathrm{mM} \mathrm{CaCl}_{2}$. The reaction was incubated at $60{ }^{\circ} \mathrm{C}$ for $3 \mathrm{~h}$ to convert all cellobiose into glucose. Overall, the study of Gefen and coworkers [43] suggested that spatial proximity of $\beta$-glucosidase to cellulosomes is a crucial parameter that influences saccharification efficiency. To corroborate the finding of Gefen et al., Li et al. [44] employed a thermotolerant BGL from Caldicellulosiruptor sp. F32 (CaBglA) to fuse with the CohII or with the CBM3a from $\mathrm{C}$. thermocellum to generate $\mathrm{CaBglA}-\mathrm{CohII}$ and $\mathrm{CaBglA}-$ CBM3a, respectively. On Avicel, the complexations of $\mathrm{Ct}$ cellulosomes and CaBglA-CohII via CohII-DocII interaction exhibited the highest activity, then the mixed proteins of cellulosomes with $\mathrm{CaBglA}-\mathrm{CBM} 3 \mathrm{a}$, the mixture of cellulosomes with free $\mathrm{CaBglA}$, and the cellulosomes alone. In addition, the glucose production also followed this order, indicating the greatest conversion rate of CaBglA in the closeness to cellulosomes. In contrast, the accumulation of cellobiose was the greatest in the sole cellulosomes treatment, suggesting an important role of Bgl enzyme in cellulose degradation.

In the study of Moraïs and colleagues [24], a trivalent ScafGTV composed of 3 CohI(s) from thermophilic species Archaeoglobus fulgidus (G), C. thermocellum (T), and Clostridium clariflavum $(\mathrm{V})$, respectively, and the $C$. thermocellum $\mathrm{CBM} 3$ a for substrate targeting was constructed for artificial cellulosome formation (Figure 4B). The native DocI of EG Cel8A and its thermostable mutant Cel8 $\mathrm{A}^{*}$ were replaced by the DocI from A. fulgidus (g) to generate Cel8A-g and Cel8 $\mathrm{A}^{*}-\mathrm{g}$, respectively, and the free $C$. thermocellum BglA as well as its thermotolerant version $\mathrm{BglA}^{*}$ were converted into cellulosomal mode BglA-v using the DocI (v) from C. clariflavum to create BglA-v and $\mathrm{BglA}^{*}-\mathrm{v}$, respectively. The mesophilic tetravalent ScafBTFA bearing 4 divergent $\mathrm{CohI}(\mathrm{s})$ originated from Bacteroides cellulosolvens (B), C. thermocellum (T), R. flavefaciens (F), and A. cellulolyticus (A), respectively, was constructed and used as a control to compare thermostability with that of ScafGTV. Moreover, two matching DocI(s) from B. cellulosolvens (b), and R. flavefaciens (f) were used to generate Cel8 $\mathrm{A}^{*}-\mathrm{b}$, and BglA $^{*}$-f. Enzymatic activity was measured with $0.5 \mu \mathrm{M}$ free enzyme each or $0.5 \mu \mathrm{M}$ optimized DCs in $50 \mathrm{mM}$ acetate buffer ( $\mathrm{pH} 5.0)$ using $1 \%(w / v)$ Avicel as a substrate at different incubation times and temperatures. After $96 \mathrm{~h}$ of incubation at $60^{\circ} \mathrm{C}$ on $1 \%(w / v)$ Avicel, reducing sugar released from the complexation of ScafGTV:Cel8A*-g/Cel48S ${ }^{*}-\mathrm{t} / \mathrm{BglA}{ }^{*}$ $\mathrm{v}$ was the highest, followed by those from the ScafGTV:Cel8A-g/Cel48S-t/BglA-v, the thermostable free enzymes Cel8 $A^{*}-g$, Cel48S*-t, BglA*-v, and WT free enzymes Cel8A-g, Cel48S-t, and BglA-v, which indicates the superiority of the thermostable Scaf and catalytic modules in substrate saccharification at elevated temperatures (Figure 4B). As expected, the complex ScafBTFA:Cel $8 \mathrm{~A}^{*}-\mathrm{b} / \mathrm{Cel} 48 \mathrm{~S}^{*}-\mathrm{t} / \mathrm{BglA}{ }^{*}-\mathrm{f}$ only sustained thermostability at $50^{\circ} \mathrm{C}$ for $48 \mathrm{~h}$ of incubation. Recently, the Thermoanaerobacter brokii $\beta$-glucosidase CglT was fused with a DocI originated from enzyme $\mathrm{CtCel} 48 \mathrm{~S}$ to promote its incorporation into artificial cellulosomes. This is one of the most efficient thermophilic $\beta$-glucosidases (BGL) identified thus far [45]. A high ratio (i.e., four to five) of BGL to cellulases (i.e., Cel48S, Cel9K, Cel8A) on the CipA exhibited the highest activity on crystalline cellulose, however, an increased or decreased ratio of CglT to cellulases (i.e., seven CglT to two cellulases or two CglT to seven cellulases, respectively) also led to a decreased hydrolytic efficiency, which indicates that an appropriate enzymatic ratio of enzyme components in artificial cellulosomes is crucial for a robust saccharolytic activity (Figure 4C). This is in line with conclusions presented in 
the studies of Tang et al. [46] and Qi et al. [47] as an imbalance ratio of BGL to cellulase or an excessive BGL supplementation to enzyme assay buffer, respectively, did not benefit the saccharification process.

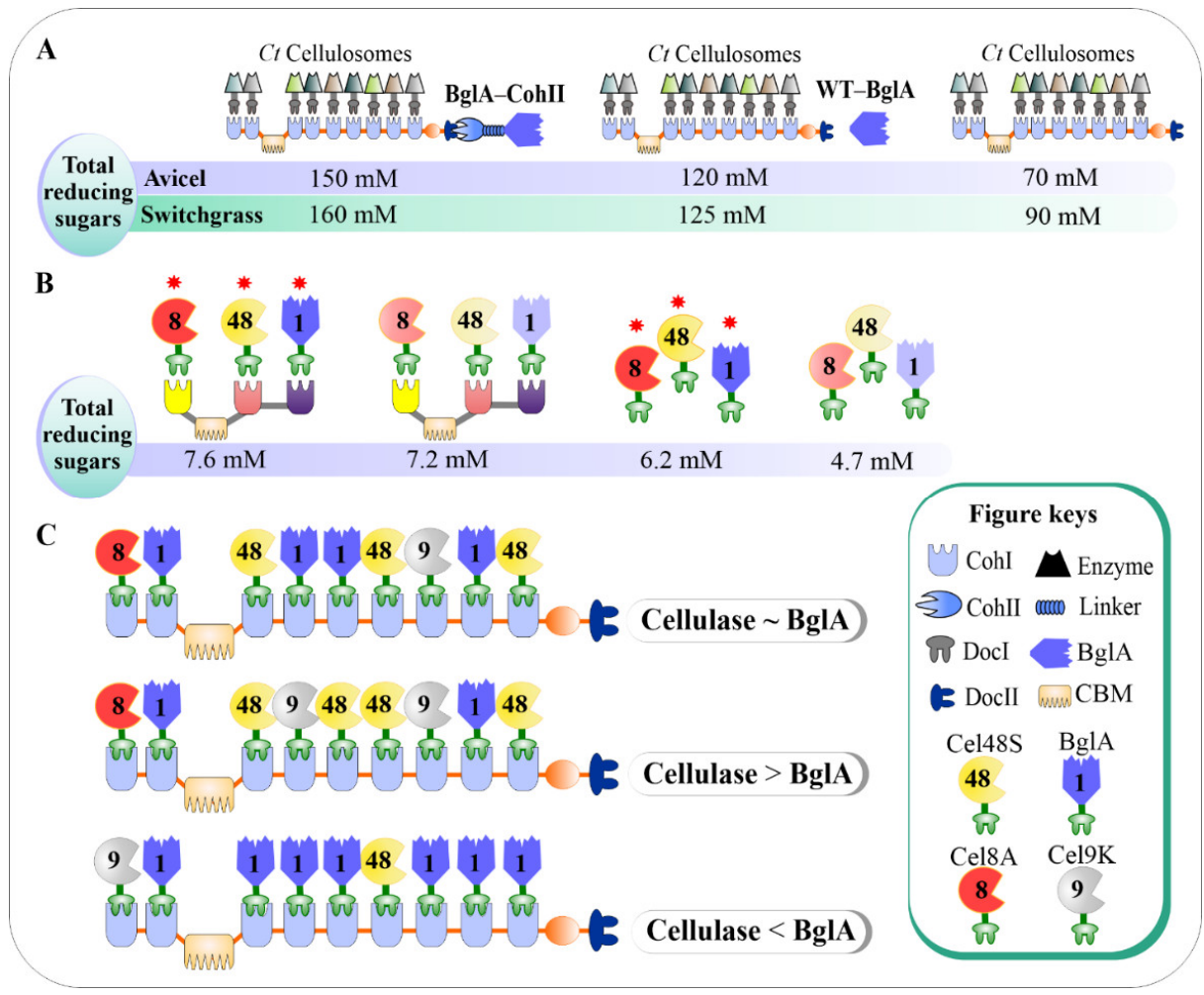

Figure 4. The incorporation of BGL into DCs aids to improve saccharification of cellulose. (A) The native non-cellulosomal BglA from $C$. thermocellum was transformed into the cellulosomal mode and integrated into Ct cellulosome via CohII-DocII interaction. (B) The thermostable mutants Cel8A, Cel48S, and BglA were used as cellulosomal enzyme components to construct trivalent artificial cellulosome. (C) The impact of ratio of BglA-to-cellulases on hydrolytic activity. Note: The asterisk $\left.{ }^{*}\right)$ indicates the thermostable mutant strain.

\subsection{Impacts of Catalytic Enzyme Positions on Enzymatic Activity of Designer Cellulosomes}

The position of catalytic subunits in the Scaf structure may govern the catalytic activity of DCs. In a study by Stern and coworkers [31], three recombinant $T$. fusca enzymes such as the processive EG Cel9A, EG Cel5A, and exoglucanase Cel48A were recombinantly generated and converted into the cellulosomal mode for DC constructions. Besides, ten chimeric Scaf(s), namely Scaf4, Scaf5, Scaf6, Scaf9, Scaf18, Scaf19, Scaf20, Scaf21, Scaf22, and Scaf23, with different designated orders of enzymes and CBMs were also produced. The enzymatic assay was carried out in $50 \mathrm{mM}$ acetate buffer (pH 5.0), $12 \mathrm{mM} \mathrm{CaCl}_{2}, 2 \mathrm{mM}$ EDTA, $10 \%(w / v)$ Avicel, incubated at $50{ }^{\circ} \mathrm{C}$ for $24-72 \mathrm{~h}$ with shaking. The two optimal trivalent Scaf configurations Scaf20 (i.e., ScafABT:a-Cel9A/b-Cel48A/Cel5A-t) with the $T$. fusca processive EG Ce19A and the $C$. thermocellum carbohydrate-binding module (CBM3a) located at the left side of Scaf20 structure, and Scaf9 (i.e., ScafTBA:Cel5A-t/b-Cel48A/aCe19A) with the T. fusca Ce19A and the $C$. thermocellum CBM3a positioned at the right side of its structure demonstrated the maximum catalytic activity on Avicel (Figure 5A). Similar results were observed when the T. fusca Cel9A, Cel5A, and Cel48A were substituted with their orthologues C. thermocellum Ce19R, Cel5G, and Cel48S, respectively (Figure 5B). Based on their hydrolytic efficiencies, the suggestion for future artificial cellulosomes design is that the processive EG should not be placed in the middle of the trivalent chimeric Scaf because the processive EG functions by cutting $\beta-1,4$-glycosidic bonds in the interior of the cellulose chain, followed by a processive cleavage of the even-numbered short 
oligosaccharides [48], its middle position within the trivalent Scaf likely restricted its movement along the substrate. In contrast, the processive EG should be located close to a CBM in the Scaf to properly fulfill its catalytic function. The third conclusion that can be drawn is that two enzymes with parallel characteristics (i.e., processive Cel9A and Cel5A from T. fusca or processive Cel9R and Cel5G from C. thermocellum) should not be placed in proximity with each other since this might lead to an unnecessary functional competition between them.

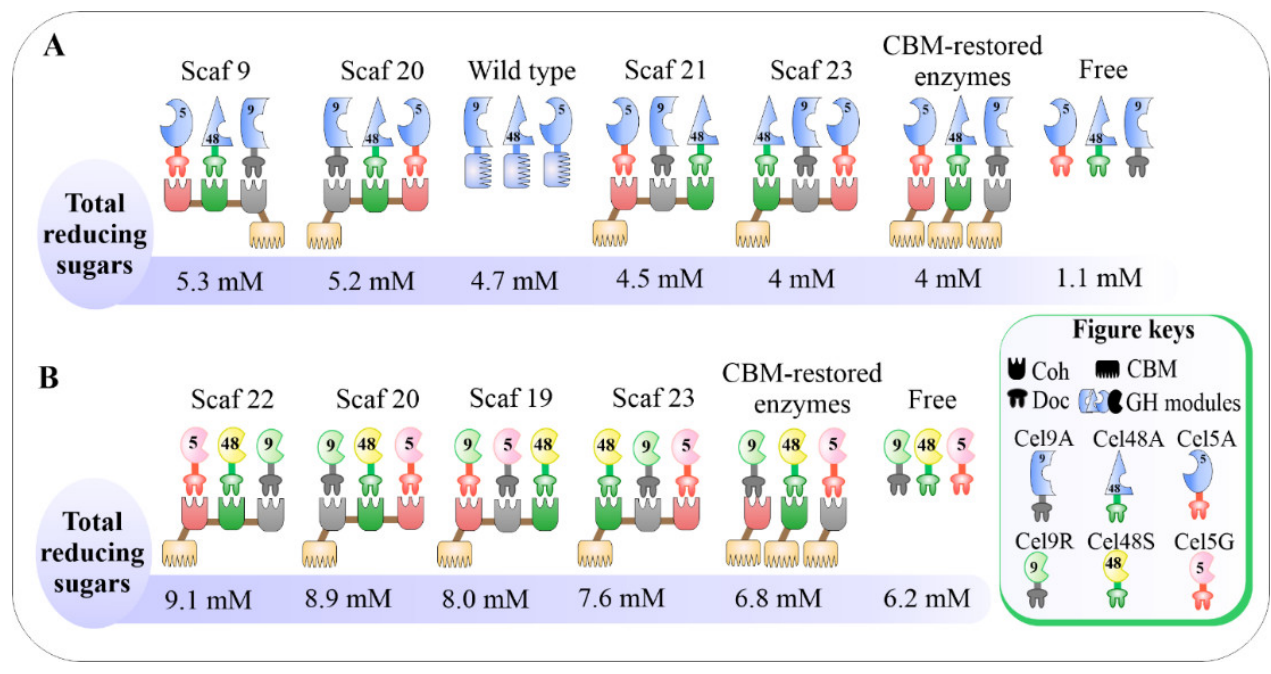

Figure 5. Influences of enzyme positions on activity of chimeric trivalent cellulosomes. (A) Hydrolysis of Avicel by T. fusca-based trivalent cellulosomes. (B) Avicel degradation by C. thermocellum-based trivalent cellulosomes.

\subsection{Impact of Mechanical Stability of CohI on Hydrolytic Activity of Designer Cellulosomes}

The mechanical stability of CohI within a Scaf is an important parameter since it impacts the catalytic activity of cellulosomes. Although the nine CohI(s) display a high level of sequence identity [49], their robustness against mechanical stress appears to be dramatically different [50]. On the CipA protein, the region between the CBM3a and the DocII was called the connecting region, while the region that consists of CohI-1, and CohI-2 was called the external region. Previous studies revealed that Coh(s), which were located in the connecting region, demonstrated higher mechanical stability in comparison to those positioned in the external region [50,51]. In a recent study of Galera-Prat et al. [52] the low mechanical stability CohI-1, with unfolding force $\left(\mathrm{F}_{\mathrm{U}}\right)=124 \pm 25 \mathrm{pN}$ at $400 \mathrm{~nm} / \mathrm{s}$ of pulling velocity, was used to produce $\mathrm{C} 1$ and E1, and the high mechanical stability CohI-7, with $\mathrm{F}_{\mathrm{U}}=480 \pm 77 \mathrm{pN}$ at $400 \mathrm{~nm} / \mathrm{s}$ of pulling velocity, was employed to generate C7 and E7 (Figure 6). The resulting C1, E1, C7, and E7 were anchored on an artificial monovalent Scaf at predesignated positions, and then the monovalent Scaf was allowed to concurrently bind to a polystyrene microparticle, which mimicked bacterial cell surface, via a CohII of the anchoring protein SdbA. Two artificial monovalent ScafC1 and ScafC7 were designed to have one $C 1$ and $C 7$, respectively, placed between the CBMs and the $X$ module/DocII (XDocII). The other ScafE1 and ScafE7 carrying one E1 and E7, respectively, positioned in the external region. Cel5A, a free EG from the thermophilic bacterium $T$. fusca, which was transformed to cellulosomal mode by fusing a DocI of the Xyn10Z from C. thermocellum, was employed as a DocI-bearing enzyme. The complexation of ScafC1:Cel5A, ScafC7:Cel5A, ScafE1:Cel5A, and ScafE7:Cel5A was confirmed by SDS-PAGE and these monovalent cellulosomes also showed similar hydrolytic activity when compared each other, but higher than that of the free Cel5A, maybe due to the targeting effect of the CBM3a in the monovalent cellulosomes. The monovalent cellulosomes were attached onto the CtS1-coated microparticle through a CohII of the anchoring Scaf SdbA to generate the bound ScafC1:Cel5A + CtS1-coated microparticle, ScafC7:Cel5A + CtS1-coated 
microparticle, ScafE1:Cel5A + CtS1-coated microparticle, and ScafE7:Cel5A + CtS1-coated microparticle complexes, and then subjected to mechanical stress. Under high mechanical stress, the activities of monovalent cellulosomes in their bound and free state were measure. To form the monovalent cellulosome complex, $0.5 \mu \mathrm{M}$ enzyme was incubated with the monovalent Scaf in a 1:1 ratio. The reaction was assayed in the reaction buffer containing $50 \mathrm{mM}$ Tris (pH 7.4), $300 \mathrm{mM} \mathrm{NaCl}, 1 \mathrm{mM} \mathrm{CaCl} 2,1 \mathrm{mg} / \mathrm{mL}$ BSA, 5-20\% (w/v) Avicel, incubated at $37^{\circ} \mathrm{C}$ for $60 \mathrm{~min}$. As a result, only the hydrolytic profile of ScafC1:Cel5A + $\mathrm{CtS1-coated} \mathrm{microparticle} \mathrm{complex} \mathrm{was} \mathrm{negatively} \mathrm{influenced} \mathrm{while} \mathrm{the} \mathrm{others'} \mathrm{activities}$ remained indistinguishable (Figure 6). According to the authors [52], this could be explained by the low mechanical stability of $\mathrm{C} 1$ that prevented the binding of the monovalent ScafC1:Cel5A to the CtS1-coated microparticle. However, in our opinion, the release of the monovalent ScafC1:Cel5A from the ScafC1:Cel5A + CtS1-coated microparticle complex is not as important as the release of the enzyme Cel5A from the ScafC1:Cel5A structure since it was the Cel5A that took responsibility for the hydrolysis of Avicel, but not the cell surface-mimicking microparticle. Moreover, the finding from a report of Hong et al. [53] showed that the deletion of the C-terminal DocII caused the detachment of cellulosomes from the cell surface, only negatively affecting $9 \%$ of the cellulose hydrolysis rate, which suggests a small contribution of cellulosome-cell synergy. Therefore, we preferably agree with the suggestion made in the previous study [51] that the higher unfolding rate of $\mathrm{C} 1$, when subjected to a force pulse, might trigger the release of enzyme-bearing DocI from its structure.

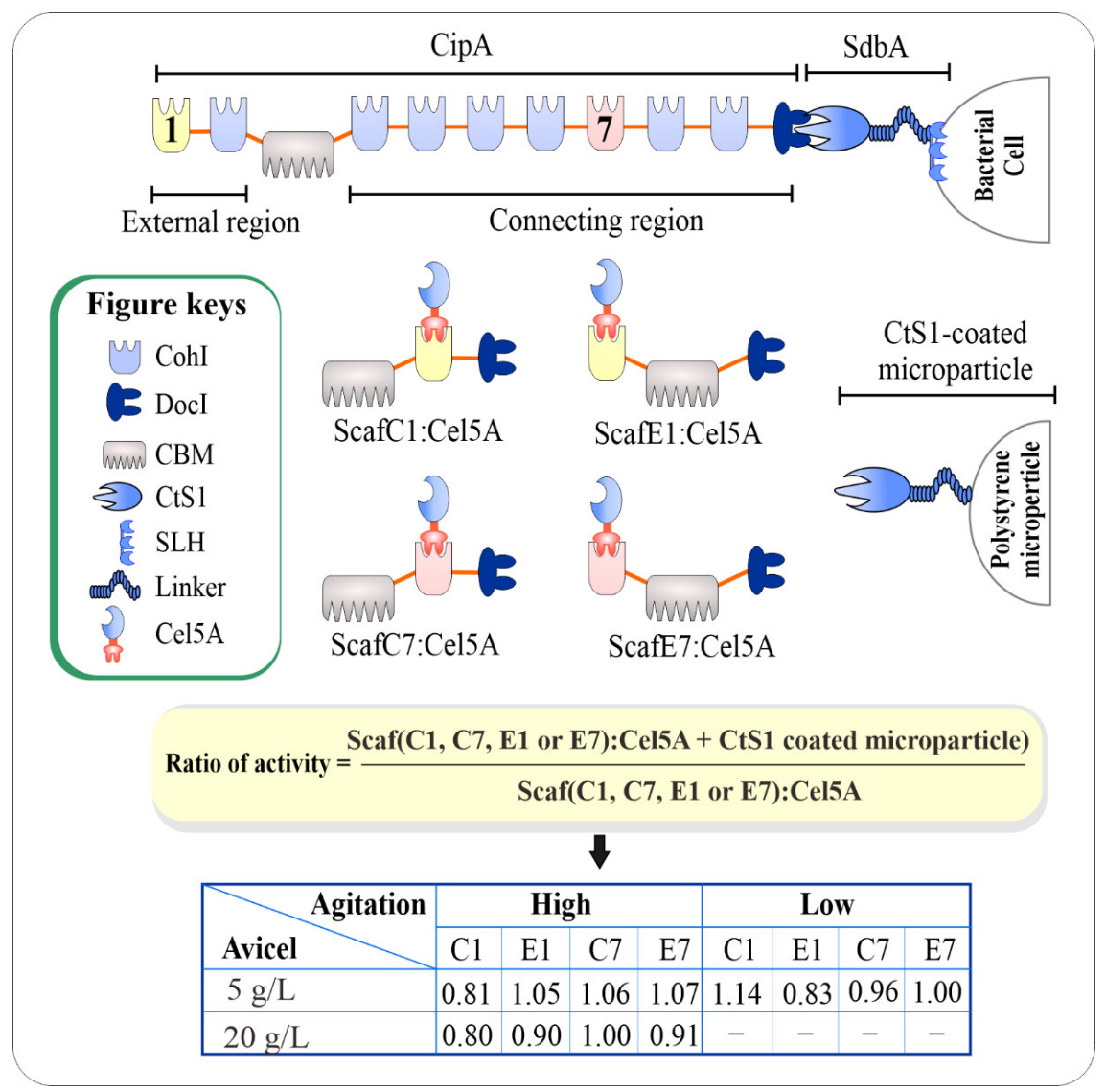

Figure 6. (From the top) The CohI located in the external and connecting regions on the CipA scaffoldin protein were used to construct mini-Scaf. Mechanically unstable Coh1 was positioned between CBM3a and DocII (ScafC1) or outside of the CBM3a (ScafE1), and mechanically stable Coh7 was placed between CBM3a and DocII (ScafC7) or outside of the CBM3a (ScafE7). The complexations of ScafC1:Cel5A, ScafE1:Cel5A, ScafC7:Cel5A, and ScafE7:Cel5A was bound to CtS1coated microparticle for biomimetic cellulosome construction. 


\subsection{Incorporation of Hyper-Thermophilic Enzymes into Designer Cellulosomes}

Artificial cellulosomes with hydrolytic enzyme components derived from mesophilic bacteria, cellulolytic fungi, and the mildly thermophilic $C$. thermocellum have long been developed [54]. However, for a broader spectrum of industrial applications, better thermostable DCs are highly demanded. At $78^{\circ} \mathrm{C}$, the hyper-thermophilic, anaerobic bacterium Caldicellulosiruptor bescii degrades the unpretreated switchgrass at high substrate loading (200 g/L) [55] and Kataeva et al. [56] found that this bacterium solubilized carbohydrate and lignin concurrently. The $\mathrm{CbCel} 9 \mathrm{~A} / \mathrm{Cel} 48 \mathrm{~A}$ is the most abundant of the carbohydrateactive enzymes (CAZymes) in the C. bescii exoproteome (representing almost $50 \%$ of the $C$. bescii exoproteome), and the most efficient single catalytic enzyme ever tested for biomass depolymerization [57]. This bifunctional enzyme consists of one family 9 processive EG Cel9A-CBM3c, one family 48 cellobiohydrolase Cel48A, and two family 3b CBM3b modules [58]. These elements were linked together by proline/threonine-rich linker peptides (Cel9A-CBM3c-CBM3b-CBM3b-Cel48A). Recently, in a study by Kahn et al. [17], the potent Cel9A/Cel48A originated from C. bescii DSM 6725 was chosen for designing artificial cellulosomes. Technical challenge did not allow an adequate expression of a full-length DocI-bearing Cel9A/Cel48A in E. coli, thus separated catalytic modules Cel9A and Cel48A were used for the conversion into the cellulosomal mode (Figure 7A). In addition, a glycoside hydrolase family 5 (GH5) EG Cel5D with a CBM28, which acts in synergy with Cel9A/Cel48A, was selected for incorporating into the artificial cellulosomes. Since $C$. bescii only produces free enzymes, three pairs of CohI-DocI, namely T-t, V-v, and G-g from C. thermocellum ATCC 27405, C. clariflavum, and the hyper-thermophilic archaeon A. fulgidus, respectively, were used to transform the free enzymes C. bescii Cel9A/Cel48A and Cel5D into the cellulosomal modes, creating the resulting chimeric Cel5D-g, Cel5D-v, Cel5D-t, Cel9A-sl-v, Cel48A-sk-t, Cel9A-lk-v, and Cel48A-lk-t. (Note: sk is a short linker of 3-7 aa, and $\mathrm{lk}$ is a long linker of $73 \mathrm{aa}$ ). Accordingly, three monovalent Scaf each carrying a single CohI and a CBM3a from C. thermocellum (i.e., ScafG, ScafT, ScafV) and one trivalent Scaf bearing $3 \mathrm{CohI}(\mathrm{s})$ (i.e., ScafGTV) were designed (Figure 7A). After inoculated at $75^{\circ} \mathrm{C}$ for $24 \mathrm{~h}$, all three complex structures ScafG:Cel5D-g, ScafT:Cel5D-t, and ScafV:Cel5D-v almost maintained their stability $(92-100 \%)$, whereas $35 \%, 32 \%$, and $42 \%$ reductions in the stability of the individual unbound enzymes Cel5D-g, Cel5D-t, and Cel5D-v were observed, respectively. Under the same incubation condition, the stabilities of individual chimeric ScafG, ScafT, and ScafV were reduced by $26 \%, 11 \%$, and $40 \%$, respectively. The trivalent ScafGTV alone showed $100 \%$ stability at $70{ }^{\circ} \mathrm{C}$ and $60 \%$ at $75{ }^{\circ} \mathrm{C}$ for $24 \mathrm{~h}$. The complexation of ScafGTV with any single form of the chimeric Cel5D enzyme, termed ScafGTV:Cel5Dg, ScafGTV:Cel5D-t, ScafGTV:Cel5D-v, also exhibited an absolute stability at $70{ }^{\circ} \mathrm{C}$ and decreased to $70-85 \%$ at $75{ }^{\circ} \mathrm{C}$ after $24 \mathrm{~h}$ of incubation. Intriguingly, the complexation of ScafGTV with all 3 forms of Cel5D enzyme, termed ScafGTV:Cel5D-g/Cel5D- $t / C e l 5 D-v$, was much stable at $75{ }^{\circ} \mathrm{C}$ with $96 \%$ stability. The optimized $0.05 \mu \mathrm{M}$ enzyme concentration was used to compare the activity of all the free enzyme and the single enzymes bound to their monovalent Scaf. For cellulosome complex formation, each Scaf was incubated with its corresponding enzymes at $37^{\circ} \mathrm{C}$ for $2 \mathrm{~h}$ in the buffer containing TBS, $10 \mathrm{mM} \mathrm{CaCl}$, and $0.05 \%$ Tween. The enzymatic assay was performed on $4 \%(w / v)$ Avicel at $60{ }^{\circ} \mathrm{C}$ and $75^{\circ} \mathrm{C}$ for $24-72 \mathrm{~h}$ in $50 \mathrm{mM}$ acetate buffer, $\mathrm{pH} 5.5,900 \mathrm{rpm}$. With regards to the effects of linker length on DC activities, the DC with long-linker Cel9A-lk-v appeared to have higher activity than other DCs with short-linker Cel9A-sk-v (Figure 7B). In a previous study, Caspi et al. [59] also found that length of the linker between catalytic module and the DocI had little effect of the activity of hydrolytic enzyme. Instead, the location of the DocI, at the N- or C-terminal of the enzyme, likely had more effect on enzyme activity. It is noteworthy that most cellulosomal enzymes bear DocI on the C-terminal sides of the catalytic modules, therefore, the fusion position of any heterologous DocI to catalytic entities should be thoroughly scrutinized. Tang et al. [46] noticed that natural linkers from $T$. reesei CBH1 and C. cellulovorans EngB improved the activity of Sf-dBGL1 by 2-fold, whereas the synthetic linker from a commercial plasmid pYD1 did not. In contrast, the synthetic linker 
was found to increase the activity of enzyme Te-dCBH1, but the naturally derived linkers did not. Especially, for the Ct-CelA, none of the three linkers could enhance its activity. Based on these instances, we might assume that the impacts of linkers on enzyme activity may vary case by case, thus no consensus on this issue has been reached yet.

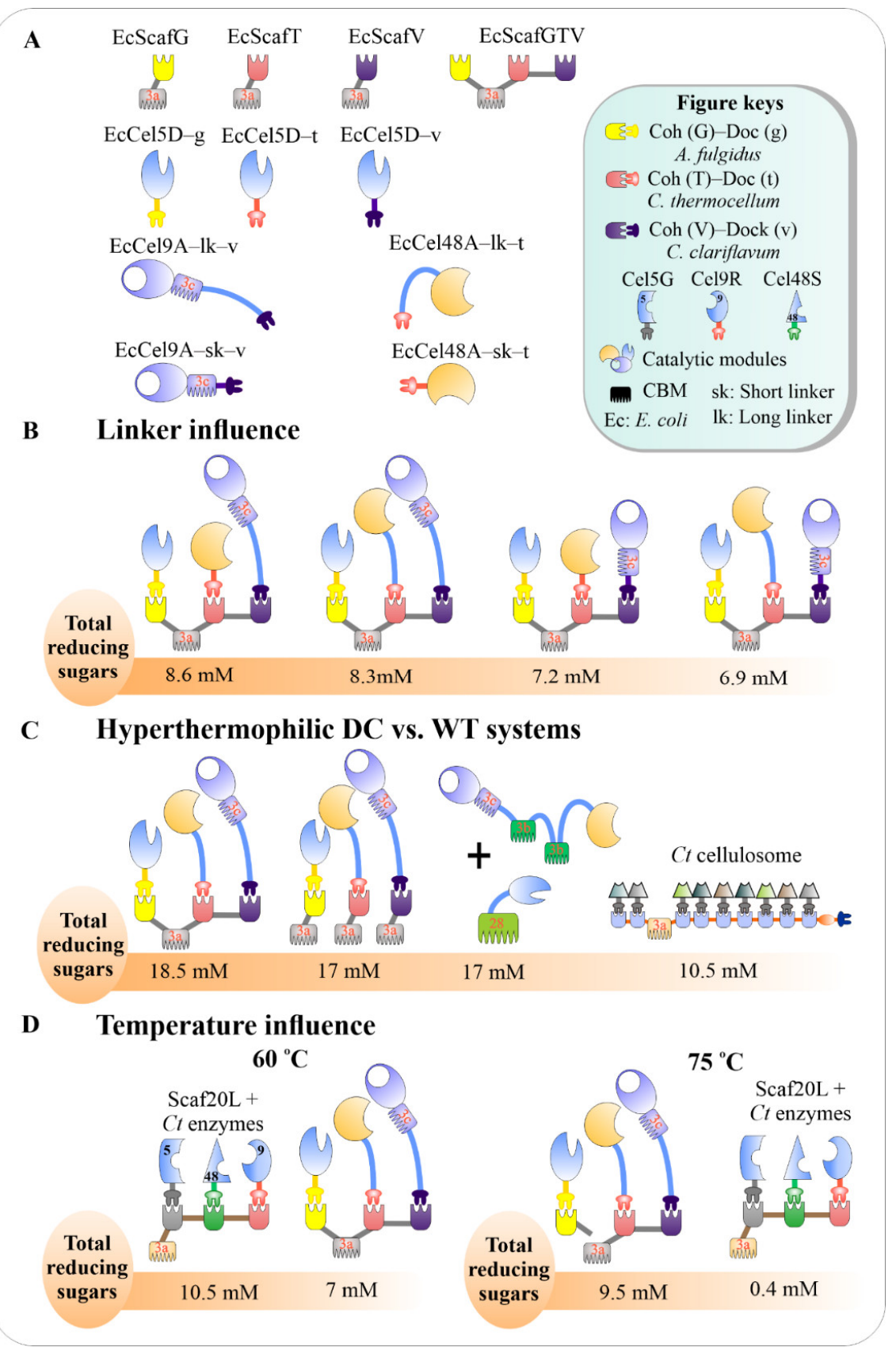

Figure 7. Development of E. coli-based DC. (A) Conversion of the wild-type (WT) C. bescii Cel9A, Cel48A into chimeric forms using E. coli as an expression host. (B) Influence of linker length in DC enzyme components on hydrolytic efficiency ( $24 \mathrm{~h}$ of incubation at $75^{\circ} \mathrm{C}, 4 \%(w / v)$ Avicel). (C) Comparison of hydrolytic activities between C. bescii-based DC, chimeric C. bescii enzymes, WT C. bescii enzymes, and native $C t$ cellulosome, (72 h of incubation at $75^{\circ} \mathrm{C}, 4 \%$ ( $\left.w / v\right)$ Avicel). (D) Effects of temperature on the activities of $C$. thermocellum-based DC and C. bescii-based DC (72 $\mathrm{h}$ of incubation at $75{ }^{\circ} \mathrm{C}, 4 \%(w / v)$ Avicel).

After $72 \mathrm{~h}$ of incubation at optimal temperature $60^{\circ} \mathrm{C}$ for $\mathrm{C}$. thermocellum enzymes, with the synergy of Cel48S and Cel9R [60], the C. thermocellum-based DC (i.e., ScafTBA:Cel5G- 
$\mathrm{t} / \mathrm{b}-\mathrm{Cel} 48 \mathrm{~S} / \mathrm{a}-\mathrm{Ce} 19 \mathrm{R})$ [31] produced higher reducing sugar release than the ScafGTV:Cel5D$\mathrm{g} / \mathrm{Cel} 48 \mathrm{~A}-\mathrm{lk}-\mathrm{t} / \mathrm{Cel} 9 \mathrm{~A}-\mathrm{lk}-\mathrm{v}$, indicating a predominant efficiency of the $\mathrm{C}$. thermocellum enzymes at mild thermophilic conditions. However, after $72 \mathrm{~h}$ of incubation at $75{ }^{\circ} \mathrm{C}$, an opposite situation was observed as the complexation of ScafGTV:Cel5D-g/Cel48A-lkt/Cel9A-lk-v showed a far higher saccharolytic activity than that of the C. thermocellumbased DC and even higher than that of the native $C$. thermocellum cellulosome whose cellulose-degrading capacity dramatically lost at such a higher temperature (Figure 7C,D). Synergy between enzymes, however, was not observed in the C. bescii-based DCs. In fact, the catalytic efficiencies of the individual bound Cel48A-lk-t and Cel48A-sk-t and their unbound forms were dramatically low on Avicel due to the lack of an appropriate glycosylation system in the E. coli XL1 cells [61].

\subsection{Effects of Glycosylation on Enzyme Activity}

The lack of a proper glycosylation system in E. coli seems to prevent $C$. bescii enzymes from fully expressing their capability [17]. Therefore, to improve the cellulolytic activity of the DCs through glycosylation, in a recently published paper, Kahn and coworkers [61] used C. bescii as an expression host to produce glycosylated CbCel9A-lk-v, CbCel48A-lk-t, and chimeric CbScaf-GTV. The DocI-bearing Cel5D failed to express in C. bescii and the

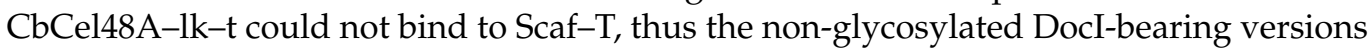
of Cel48A and Cel5D, with short linker, were expressed in E. coli to produce EcCel48Ask-t and EcCel5D-g, respectively (Figure 8A). Additionally, the other DC components from their previous study [17] such as EcScaf-GTV and EcCel9A-lk-v were used to form E. coli-based DC (Figure 8A). As a result, the C. bescii-based DC (CbScafGTV:EcCel5D-

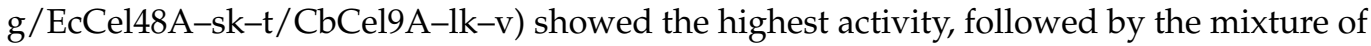
unbound individual enzymes EcCel5D-g + EcCel48A-sk-t + CbCel9A-lk-v, E. coli-based DC (EcScafGTV:EcCel5D-g/EcCel48A-sk-t/EcCel9A-lk-v), and the cocktail of unbound individual enzymes EcCel5D-g + EcCel48A-sk- + EcCel9A-lk-v (Figure 8B,C). The result revealed that glycosylated enzymes, even in their unbound form, can express a comparable activity relative to the unglycosylated DCs. Moreover, the attachment of O-linked $\alpha$-1,2-galactose-containing oligosaccharides on the linker of catalytic modules likely has more impact on the overall DC activity than the attachment of oligosaccharides on the Scaf protein. Notably, glycosylation also improves thermostability of the DC, suggesting that a posttranslational modification is an important part in DC engineering (Figure 8D). The findings from Kahn and coworkers $[17,61]$ indicate that the hyper-thermotolerant cellulolytic enzymes from C. bescii, with a marvelous thermotolerant property, are potential catalysts for biomass decomposition. A better thermotolerance enzyme also makes enzyme recycling more feasible and cellulosic substrates-based biofuels more cost-effective relative to the fossil-derived fuels. However, the discrepancy in released reducing sugar data from these two reports remains to be explained because the authors used the same protocol for enzyme assay. For instance, with the same enzyme assay protocol with $4 \%(w / v)$ Avicel, $72 \mathrm{~h}$ of incubation at $75^{\circ} \mathrm{C}$, in their previous paper [17], the authors found approximately $18.5 \mathrm{mM}$ sugar released when using E. coli-based DC (EcScafGTV:EcCel5D-g/EcCel48A-lk$\mathrm{t} / \mathrm{EcC}$ l9A-lk-v), whereas in their second paper [62], they only recorded about 7.3-7.8 mM reducing sugar released from the EcScafGTV:EcCel5D-g/EcCel48A-sk-t/EcCel9A-lk-v. Note that no statistically significant difference was found in the catalytic efficiency of the EcCel48A-lk-t and EcCel48A-sk-t [17]. The inconsistency makes their conclusion less pronounced because the glycosylated C. bescii-based DC (CbScafGTV:EcCel5D-g/EcCel48Ask-t/CbCel9A-lk-v), which was stated as the best DC in this study, only produced roughly 11-12 $\mathrm{mM}$ reducing sugar [61]. 


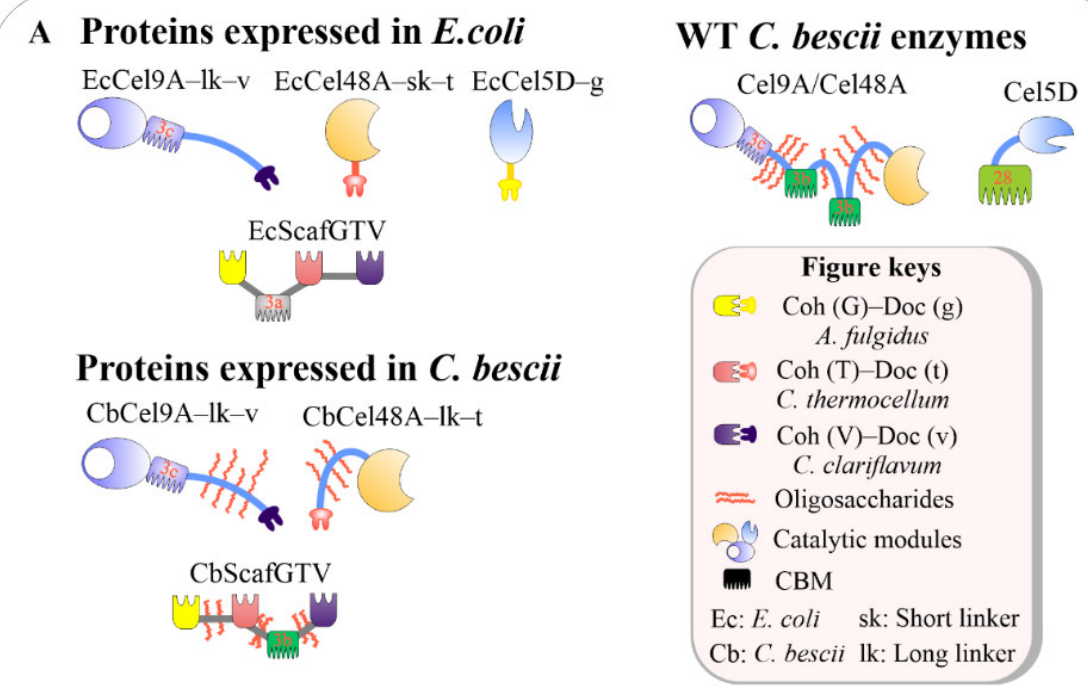

B Glycosylated DC vs. Non-glycosylated

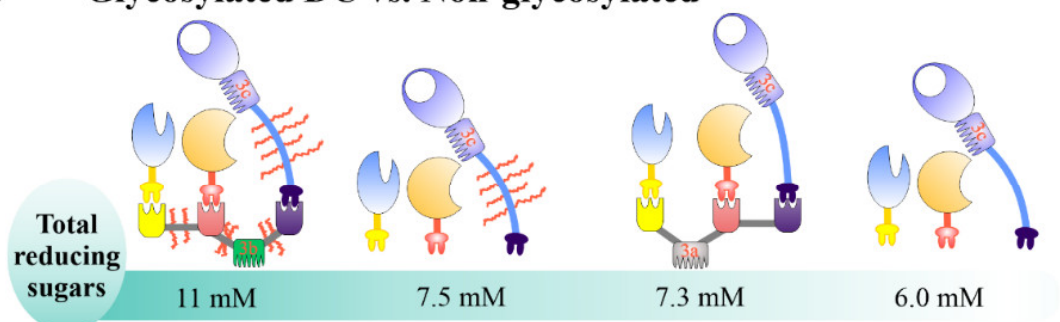

C Hydrolytic activities of different glycosylated modules

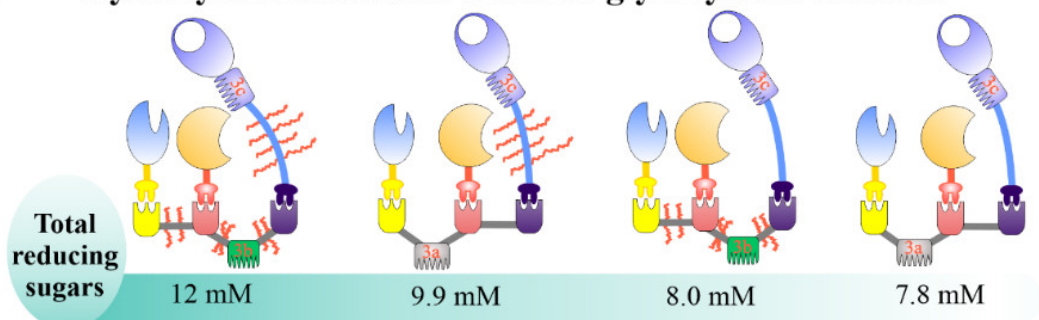

D Temperature influence

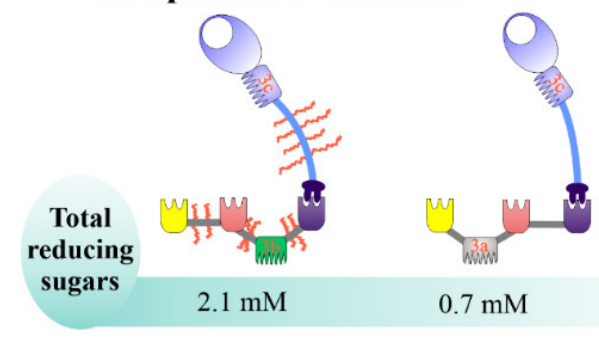

Figure 8. Development of C. bescii-based DC. (A) Conversion of the WT C. bescii enzymes into chimeric forms using E. coli or C. bescii as an expression host. (B) Influence of linker length in DC enzyme components on hydrolytic efficiency (24-h incubation at $75{ }^{\circ} \mathrm{C}, 4 \%(w / v)$ Avicel). (C) Comparison of hydrolytic activities between $C$. bescii-based DC, chimeric $C$. bescii enzymes, WT C. bescii enzymes, and native $\mathrm{C}$. thermocellum cellulosome, (72-h incubation at $75{ }^{\circ} \mathrm{C}, 4 \%(w / v)$ Avicel). (D) Effects of temperature on the activities of C. thermocellum-based DC and C. bescii-based DC (Heat treatment at $85^{\circ} \mathrm{C}$ for $3 \mathrm{~h}$, followed by $16-\mathrm{h}$ incubation at $75^{\circ} \mathrm{C}, 4 \%(w / v)$ Avicel). 


\section{Conversion of Non-Cellulolytic Biofuel Microbes into Consolidated Bioprocessing Microbes}

\subsection{Creation of Cellulolytic Bacillus Subtilis}

Although well-known for the robust cellulosome machinery, the slow growth rate of C. thermocellum with strictly anaerobic culturing conditions, the highly cost of cellulosome production due to the low productivity, and its metabolic intermediates likely appear undesirable for industrial applications [62]. The Gram-positive bacterium Bacillus subtilis has been commonly used as a workhorse to produce numerous recombinant proteins [63]. As a super CBP microbe remains unfound, a co-culturing system that harmoniously combines one cellulolytic $B$. subtilis and another potent bioethanol-producing yeast is likely a feasible approach. In the study of Chang et al. [22], two polycistronic operons with the same gene collection but different orders, namely Type-I: cipA-cel9K-cel48S-cel9R-sdbA-cel8Axyn10C-xyn10Z and Type-II: cipA-xyn10Z-xyn10C-cel8A-sdbA-cel9K-cel9R-cel48S, were constructed using the ordered gene assembly in B. subtilis (OGAB) method [64] to evaluate the influence of enzyme position on catalytic performance (Figure 9). Genes in these two operons were driven by a strong, thermo-inducible Pr promoter from phage lambda [65]. To measure the enzyme activity, $50 \mu \mathrm{L}$ of the 25 -fold condensed culture supernatant of engineered B. subtilis was mixed with $50 \mu \mathrm{L}$ of $50 \mathrm{mM}$ sodium acetate ( $\mathrm{pH} 5.0), 2 \%(w / v)$ PASC or $2 \%(w / v)$ xylan. The type-I engineered $B$. subtilis strain released higher reducing sugars than the type-II strain when growing on Avicel and filter paper, whereas the type-II strain exhibited more robust capability of degrading Napier grass powder than the type-I strain, suggesting an important role of xylanases enzyme in the decomposition of native plant biomass. The finding was also in agreement with the finding of Stern et al. [31], in that the enzyme position within a given enzyme complex, e.g., DCs, is of importance for the optimum solubilization of a specific substrate.

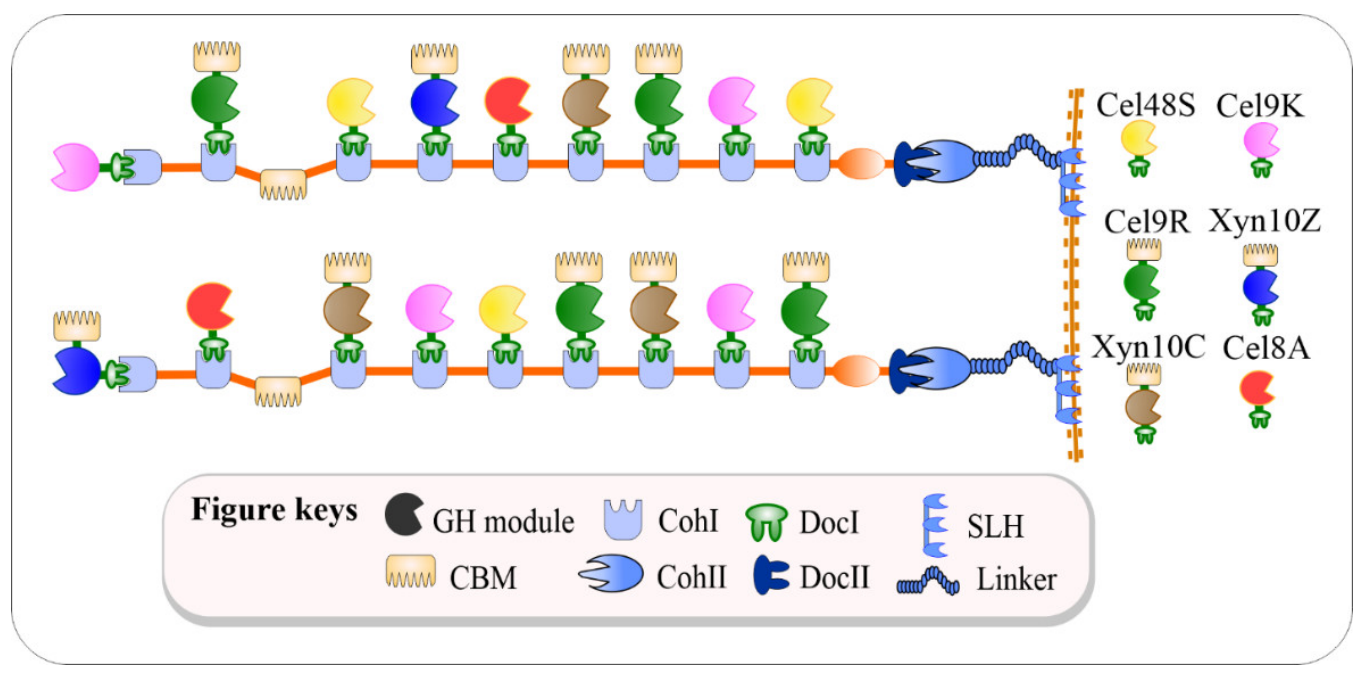

Figure 9. Two cell-surface displayed artificial cellulosomes anchored on B. subtilis cells. The upper operon represents the order of enzyme-encoding genes where the $\mathrm{CBH}$ and $\mathrm{EG}$ genes were placed near the Pr promoter. The lower operon displays enzyme-encoding genes where the Xyn genes were positioned near the Pr promoter.

\subsection{CBP-Enabling Saccharomyces cerevisiae}

$\mathrm{CBP}$ is a promising approach to reduce the cost of biofuel production from cellulosic biomass. However, the well-known biofuel workhorses such as S. cerevisiae and Kluyveromyces marxianus lack a hydrolytic enzyme system to efficiently degrade cellulose and hemicellulose. Advances in modern genetic engineering and synthetic biology enable biofuels scientists to introduce many saccharolytic genes derived from divergent species, both prokaryotes and eukaryotes, into the target host cells to make them engineered CBP microbes. The direct conversion of cellulose into bioethanol through yeast surface- 
displayed synthetic cellulosomes is a promising approach for CBP [46]. In a study by Fan et al. [11], individual minicellulosomes, each carrying a primary ScafI, an EG (CelCCA), a cellobiohydrolase (CelCCE), and a BGL (Cel_2454) from C. cellulolyticum, were engineered to display on cell surface of $S$. cerevisiae. The enzymes BGL, EG, and $\mathrm{CBH}$ were fused with DocI-1 from C. cellulovorans, DocI-2 from C. cellulolyticum, and DocI-3 from C. thermocellum, respectively. The primary ScafI contained a C-terminal DocII, a CBM, and three CohI-1, CohI-2, and CohI-3 that were able to interact with their matching DocI-1, DocI-2, and DocI-3, respectively. The ScafII carrying one to four CohII(s) that mediate the anchoring of minicellulosomes onto cell surface. The display of ScafII was mediated using a pYD1 Yeast Display Vector Kit containing a yeast-secretion signal. The supernatants containing cellulases and miniScaf were mixed in $100 \mathrm{mM}$ Tris- $\mathrm{HCl}$ buffer (pH 5.5), $10 \mathrm{mM} \mathrm{CaCl}_{2}$, $2 \mathrm{~h}$ of incubation at $4{ }^{\circ} \mathrm{C}$ for minicellulosome assembly. The reaction was conducted by incubating the minicellulosomes in $100 \mathrm{mM}$ Tris- $\mathrm{HCl}$ (pH 5.5), $10 \mathrm{mM} \mathrm{CaCl}_{2}$, at $30{ }^{\circ} \mathrm{C}$ for $16 \mathrm{~h}$ with $0.1 \%(w / v)$ Avicel, PASC or CMC. However, ethanol titer produced by the recombinant S. cerevisiae EBY was extremely low with only $1.41 \mathrm{mg} / \mathrm{L}$ and $1.1 \mathrm{mg} / \mathrm{L}$ on $0.1 \%$ $(w / v)$ Avicel and $0.1 \%$ (PASC), respectively. In a study by Liang et al. [66], five enzymes, including a GH61a (a LPMO) from Thermooascus aurantiacus, a cellobiose dehydrogenase (CDH) from Humicola insolens, a CBH and an EG from Trichoderma reesei, and a BGL from Aspergillus aculeatus were assembled onto a five-CohI C. thermocellum miniScaf [66]. This miniScaf was successfully displayed on the surface of $S$. cerevisiae through an AGA1 and AGA2 yeast display system, and the engineered S. cerevisiae produced $2.7 \mathrm{~g} / \mathrm{L}$ ethanol on $0.1 \%$ PASC.

A double-layered cellulosome was synthesized in a study by Tang et al. [46] where an artificial ScafAGA3 bearing the repeated N-terminus of Aga1p (tAga1p) was displayed on the cell surface of S. cerevisiae through the Aga1p C-terminal domain. The ScafAGA3 was used as an anchoring protein via Aga1p-Aga2p linkage and the ScafCipA3 functioned as the primary Scaf for cellulase assembly (Figure 10). The ScafCipA3, which contained three CohI(s) from $C$. thermocellum on its structure, carried three cellulases from divergent microbes via CohI-DocI interaction. For the conversion of free cellulases into cellulosomal mode, a BGL from Saccharomycopsis fibuligera, a CBH from Talaromyces emersonii, and an EG CelA from $C$. thermocellum were fused with the traditional $C$. thermocellum DocI(s). The novel disulfide bonds showed higher display efficiency of the ScafAGA3 on the cell surface in comparison with that of the conventional CtScafCipA3. The result demonstrates that the covalent disulfide bonds of tAga1p-Aga2 appeared to outperform the non-covalent bonds of the conventional CohI-DocI pair in cellulase assemblage. For enzyme activity measurement, the enzymes were mixed with $5 \mathrm{mM}$ p-nitrophenyl- $\beta$-Dcellobiose (pNPC) or carboxymethylcellulose sodium salt (CMC-Na) as the substrates in $50 \mathrm{mM}$ citrate buffer ( $\mathrm{pH} \mathrm{5.0)}$ at $50{ }^{\circ} \mathrm{C}$ for $30 \mathrm{~min}$ for $\mathrm{CBH}$ and $\mathrm{EG}$ measurements, respectively. The resultant engineered $S$. cerevisiae carrying the double-layered cellulosome ScafAGA5-ScafCipA3:CBH1/CelA/BGLA produced $1.52 \mathrm{~g} / \mathrm{L}$ ethanol on $1 \%(w / v)$ PASC. In summary, despite many efforts to create the CBP S. cerevisiae, the bioethanol produced by these engineered strains have been still modest due mainly to the lower efficiency of the surface-displayed cellulosomes. Some catalytic proteins assembled onto the DCs did not have sufficient ability to digest high substrate concentrations to supply an abundant fermentable sugar source for the CBP S. cerevisiae. 


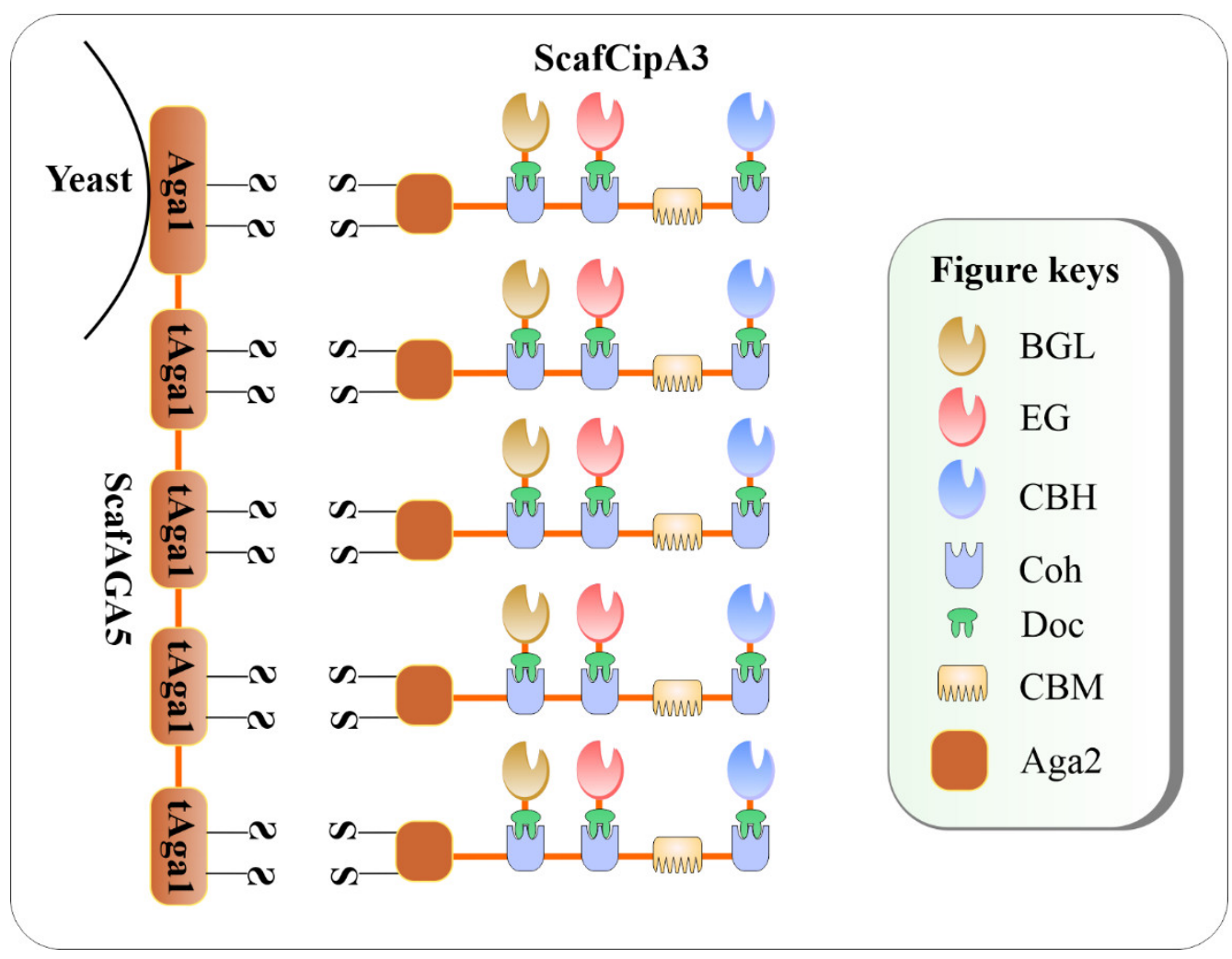

Figure 10. The attachment of trivalent Scaf on S. cerevisiae cell surface via covalent disulfide bonds of tAga1p-Aga2. This approach helps to improve surface display efficiency relative to the common CohII-DocII binding.

\subsection{CBP-Enabling Pichia pastoris}

Pichia pastoris has been widely used for the expression of diverse recombinant proteins. The limited production of endogenous secretory proteins in P. pastoris makes the purification of recombinant proteins easy [67]. Additionally, an appropriate posttranslational modification is an advantage in producing proteins with correct folding and proper biological activity. Recently, an indirect $P$. pastoris surface-display method was developed to create a CBP cell factory [68]. Instead of using the usual non-covalent interactions between CohI and DocI from C. thermocellum, the colicin E7 DNase (CE7) and its matching immunity protein $7(\operatorname{Im} 7)$ was used as a CE7-Im7 protein pair. The CE7 was mutated to inactivate DNase activity but retained its full binding affinity to generate CL7 tag, and the Im7, a cognate inhibitor of CE7, was employed to form an ultra-high-affinity IM7-CL7 protein pair $\left(\mathrm{K}_{\mathrm{D}} \sim 10^{-14}-10^{-17} \mathrm{M}\right)$ [69]. The IM7-CL7 protein pair was used as an alternative to the conventional Coh-Doc pair for cellulosome assembly (Figure 11). A CBH from Yarrowia lipolytica, an EG Ce19D from C. thermocellum DSM1237, a BGL from Thermoanaerobacterium thermosaccharolyticum, and a CBM from T. fusca were fused with N-terminal CL7 tags and recombinantly expressed in E. coli. The surface anchoring protein SED from S. cerevisiae was fused to the IM7 scaffoldin protein to mediate the attachment of the enzyme complex onto cell surface. In turn, the IM7 proteins were engineered to display for two or three times to carry two to three catalytic modules, thus generating Y-IM2 and Y-IM3 yeasts, respectively. Subsequently, the engineered P. pastoris yeasts were incubated with the E. coli lysates containing cellulosomal-mode-cellulases and CBMs to promote the assembly of minicellulosomes on cell surface via IM7-CL7 interaction. On Avicel and PASC, the engineered Y-IM2 performed better than Y-IM3 with $2.5 \mathrm{~g} / \mathrm{L}$ and $1.2 \mathrm{~g} / \mathrm{L}$ ethanol, respectively, whereas the Y-IM3 surpassed Y-IM2 on CMC substrate with up to $5.1 \mathrm{~g} / \mathrm{L}$ ethanol. Moreover, a synergistic effect on CMC hydrolysis was also observed in Y-IM3, indicating a positive relationship between the number of Scaf IM7 and the catalytic efficiency. 


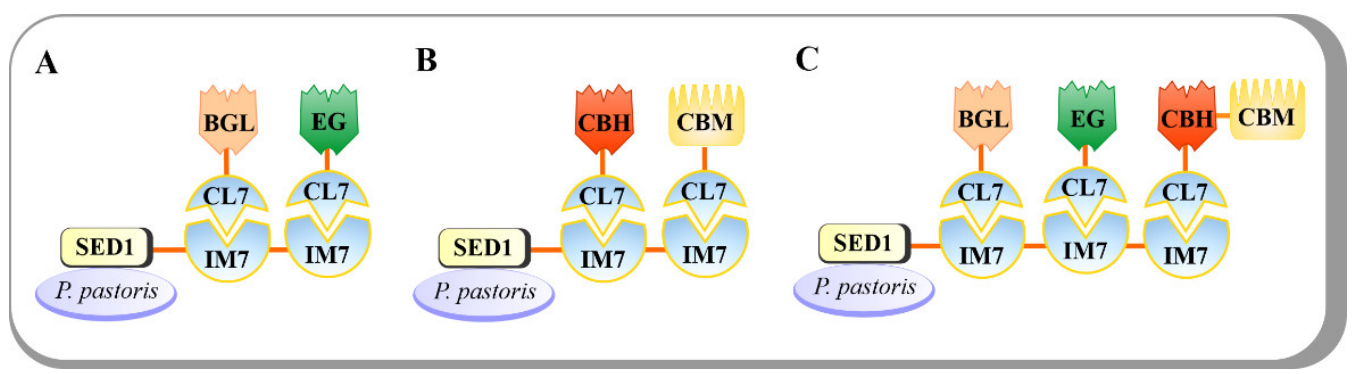

Figure 11. The novel ultra-high-affinity IM7-CL7 protein pair $\left(K_{D} \sim 10^{-14}-10^{-17} \mathrm{M}\right)$ was used for cellulase assembly onto P. pastoris cell surface. (A) The engineered P. pastoris with one BGL and one EG enzyme on its surface. (B) The engineered P. pastoris with one $\mathrm{CBH}$ and one CBM on its surface. (C) The engineered P. pastoris with one $\mathrm{CBH}$, one $\mathrm{EG}$, one $\mathrm{CBH}$, and one $\mathrm{CBM}$ on its surface.

\subsection{Consolidated Bioprocessing-Enabling K. marxianus}

In C. thermocellum, aside from bearing CohI(s) on its backbone, the CipA has a DocII subunit that interacts with the CohII on the bacterial cell surface to mediate the attachment of the entire Scaf and cellulolytic enzymes complex to the C. thermocellum cell surface. The anchoring outer layer protein B (OlpB) has seven CohII(s) subunits, so it can theoretically concurrently carry up to 63 saccharolytic enzymes. Generally, the incorporation of more catalytic enzymes onto the primary Scaf results in higher synergy for substrate decomposition [70]. The thermotolerant $K$. marxianus has several advantages (e.g., a wide range of sugars assimilation, thermo, salinity, and toxin tolerance, a wide range of $\mathrm{pH}$, high ethanol yield at elevated temperature) for industrial applications [71,72], and therefore it could be used as an alternative to $S$. cerevisiae in specific conditions. Recently, the anchoring protein OlpB was successfully introduced and expressed in K. marxianus cells by Anandharaj and coworkers [73]. In this study, lytic polysaccharide monooxygenases (LPMO), the copper-dependent enzymes, which can efficiently solubilize crystalline cellulose by cleaving polysaccharides through an oxidative mechanism, was converted to the cellulosomal mode for constructing DC. These enzymes were brought to light in the last decade and some previous studies that integrated LPMO enzyme into cellulosome complex were performed by Arfi et al. (2014) [33] and Liang et al. [66]. Apart from the LPMO from Thermoascus aurantiacus (TaLPMO) and its electron donor cellobiose dehydrogenase from Myceliophthora thermophila (MtCDH), an EG from T. reesei (TrEgIII), a synthetic $\mathrm{CBH}$ (CBHII), and a BGL from Neocallimastix patriciarum (NpaBGS) were fused with a DocI of $C$. thermocellum to create DocI-fused enzyme subunits, namely TrEgIII-t, CBHII-t, NpaBGS-t, TaLPMO- $t$, and MtCDH- $t$, respectively (Figure 12). In addition, a cell-surface protein glycosylphosphatidylonositol (GPI) from S. cerevisiae (ScGPI) was used to facilitate the anchoring of the artificial cellulosome to the $K$. marxianus cell surface because the anchoring domain of $C$. thermocellum is not suitable for eukaryotic hosts. The supernatants of red fluorescent protein (RFP)-fused DocT (RFP-DocT), OlpB-ScGPI, and CipA1B9C were mixed to form the entire cellulosome complex, namely OlpB-ScGPI:CipA1B9C:RFP-DocT, and their assembly was confirmed using an epifluorescence microscopy. The hydrolytic activity of cellulosome on $1 \%(w / v)$ Avicel was quantified by mixing the concentrated supernatants of the YP culture broth with Avicel and incubated at $40{ }^{\circ} \mathrm{C}$ for $6 \mathrm{~h}$. On the model micro-crystalline cellulose Avicel, the amounts of sugar release were significantly influenced by the number of CohI and the number of CBMs, whereas the effect of these components was less pronounced on amorphous cellulose phosphoric acid swollen cellulose (PASC) hydrolysis (Figure 12A,B). The results confirmed the decisive roles of the scaffoldin protein CipA in cellulose solubilization rate as elucidated in a previous study by Olson et al. [74]. To the best of our knowledge, this is the first time an assembly of 63 saccharolytic cellulosomal enzymes from different species was engineered and expressed on a heterologous host's surface, enabling a greater biomass degradation rate for future consolidated bioprocessing (CBP) microorganisms (Figure 12C). 


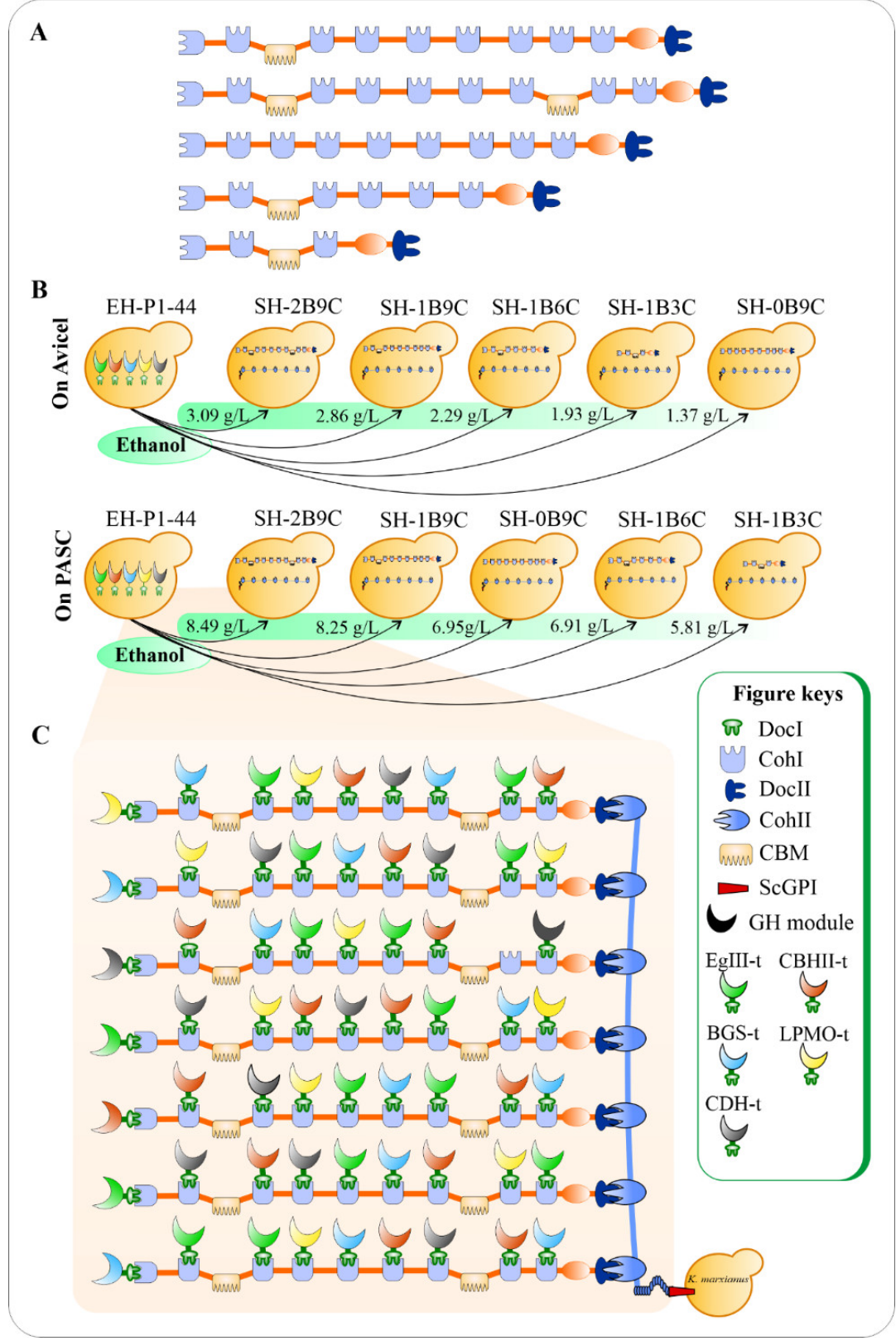

Figure 12. Engineered K. marxianus carrying the largest cellulosome complex on its cell surface. (A) (from the top) Full-length of CipA with 1 CBM3a (1B9C), full-length of CipA with 2 CBM3a(s) (2B9C), full-length of CipA without CBM3a (0B9C), truncated CipA with 6 CohI(s) + 1 CBM3a (1B6C), and truncated CipA with 3 CohI(s) + 1 CBM3a (1B3C), respectively. (B) Ethanol productivity of different engineered K. marxianus strains. On Avicel, the SH-2B9C strain yielded the highest ethanol titer, followed by the $\mathrm{SH}-1 \mathrm{~B} 9 \mathrm{C}$ strain, and the lowest ethanol concentration was found in $\mathrm{SH}-0 \mathrm{~B} 9 \mathrm{C}$ which does not have any CBM, indicating the decisive role of a CBM in crystalline cellulose hydrolysis. On PASC, however, the lowest ethanol titer was recorded in SH-1B3C strain, suggesting that the numbers of catalytic subunits, but not CBM3a(s), dictate the efficiency of amorphous cellulose solubilization. (C) The engineered K. marxianus with the whole cellulosome complex consisting of total 63 enzyme subunits from divergent species on its surface. Abbreviations in the Figure 12: B, Carbohydrate-binding module; C, Cohesin.

\section{Promise, Limitations and Future Directions}

The search more effective biomass-degrading DCs or cellulase blends is an onerous task. For further optimization of artificial cellulosomal compositions, more investigations are 
required to support a better understanding of the hydrolysis modes, especially synergistic effects between divergent cellulolytic enzymes in a whole complex. Despite some difficulties in the conversion of free enzymes into cellulosomal modes due to the incompatibility between host cells and the expression of the transgenes, this approach has been a common strategy in recent years because it enables scientists to exploit novel enzyme sources with advantageous characteristics (i.e., hyperthermal stability, lignin degrader, cellulase boosters). Furthermore, the reasons underlying unsuccessful cases of many C. thermocellum cellulosomal enzymes that could not be recombinantly produced in E. coli cells remain unknown but may be also related to the suboptimal heterologous protein expression in the host cells. Although O-linked $\alpha$-1,2-galactose-containing oligosaccharides were found on the linkers of scaffoldin proteins from $C$. thermocellum and Bacteroides cellulosolvens for decades, the impact of glycosylation on the performance of artificial cellulosomes was recently confirmed as the glycosylated DCs exhibited enhanced saccharolytic effectiveness and thermal stability. The glycosylation of DCs should therefore be taken into consideration as a new parameter for DCs construction in future studies. Besides, mechano-stability of the CohI(s) is also an important parameter for preserving net saccharification activity under great mechanical load. Furthermore, the finding of new protein pairs other than CohI-DocI pairs is a new trend noticed in some recently published papers to improve binding affinity between saccharolytic domains, scaffoldin protein, and/or cell-surface-display effectiveness.

The development of robust microbes that can ferment cellulose to biofuels or other valuable products is an interesting but challenging proposition for the biofuels industry. Despite the many efforts that have been deployed thus far to convert the non-cellulolytic ethanol producers into CBP microbes, it is likely that these engineered microbes, including S. cerevisiae, P. pastoris, and K. marxianus, could not perform well as we might expect. For instance, although well-armed with up to 63 cellulolytic enzymes on the surface, the engineered K. marxianus only produced $3.09 \mathrm{~g} / \mathrm{L}$ and $8.61 \mathrm{~g} / \mathrm{L}$ ethanol from microcrystalline cellulose Avicel and amorphous cellulose PASC, respectively, let alone the native recalcitrant biomass. These ethanol titers, though higher than any other engineered yeast cellulosome, are still quite low to make the artificial cellulolytic K. marxianus CBP ready.

Author Contributions: Conceptualization, D.M.H.-T. and T.T.M.N.; writing-original draft preparation, D.M.H.-T., T.T.M.N. and C.-C.H.; visualization, T.T.M.N.; writing-review and editing, D.M.H.-T., T.T.M.N. and C.-C.H.; supervision, C.-C.H. All authors have read and agreed to the published version of the manuscript.

Funding: This work received no external funding.

Conflicts of Interest: Authors declare that there is no conflict of interest.

\begin{abstract}
Abbreviations
A. cellulolyticus, Acetivibrio cellulolyticus; A. fulgidus, Archaeoglobus fulgidus; A. aculeatus, Aspergillus aculeatus; B. cellulosolvens, Bacteroides cellulosolvens; BGL, Beta-glucosidase; CBM, Carbohydrate-binding module; CBP, Consolidated bioprocessing; C. cellulolyticum, Clostridium cellulolyticum; C. clariflavum, Clostridium clariflavum; CMC, Carboxymethylcellulose; CMC-Na, Carboxymethylcellulose sodium salt; C. bescii, Caldicellulosiruptor bescii; CBH, Cellobiohydrolase; CohI, Type-I cohesin; CohII, Type-II cohesion; C. thermocellum, Clostridium thermocellum; DC, Designer cellulosome; DocI, Type-I Dockerin; DocII, Type-II Dockerin DP, Degree of polymerization; EG, Endoglucanase; GH, Glycoside hydrolase; H. insolens, Humicola insolens; HPAEC-PAD, High pressure anion exchange chromatography coupled with pulsed amperometric detector; K. marxianus, Kluyveromyces marxianus; lk, Long linker; PASC, Phosphoric acid swollen cellulose; pNPC, p-nitrophenyl- $\beta$-D-cellobioside; pNPG, p-nitrophenyl- $\beta$ D-glucopyranoside; R. flavefaciens, Ruminococcus flavefaciens; sk, Short linker; Scaf, Scaffoldin; SLH, Surface layer homology; T. brockii, Thermoanaerobacter brockii; T. fusca, Thermobifida fusca; T. reesei, Trichoderma reesei.
\end{abstract}




\section{References}

1. Zhivin-Nissan, O.; Dassa, B.; Morag, E.; Kupervaser, M.; Levin, Y.; Bayer, E. Unraveling Essential Cellulosomal Components of the (Pseudo)Bacteroides Cellulosolvens Reveals an Extensive Reservoir of Novel Catalytic Enzymes. Biotechnol. Biofuels 2019, 12, 1-21. [CrossRef]

2. Pauly, M.; Keegstra, K. Cell-wall Carbohydrates and Their Modification as a Resource for Biofuels. Plant J. 2008, 54, 559-568. [CrossRef]

3. Raman, B.; Pan, C.; Hurst, G.; Rodriguez, M., Jr.; McKeown, C.; Lankford, P.; Samatova, N.; Mielenz, J. Impact of Pretreated Switchgrass and Biomass Carbohydrates on Clostridium Thermocellum ATCC 27405 Cellulosome Composition: A Quantitative Proteomic Analysis. PLoS ONE 2009, 4, e5271. [CrossRef]

4. Mechaly, A.; Fierobe, H.-P.; Belaich, A.; Belaich, J.-P.; Lamed, R.; Shoham, Y.; Bayer, E. Cohesin-Dockerin Interaction in Cellulosome Assembly-A Single Hydroxyl Group of a Dockerin Domain Distinguishes Between Nonrecognition and High Affinity Recognition. J. Biol. Chem. 2001, 276, 9883-9888. [CrossRef] [PubMed]

5. Bayer, E.; Lamed, R.; White, B.; Flint, H. From Cellulosomes to Cellulosomics. Chem. Rec. 2008, 8, 364-377. [CrossRef] [PubMed]

6. Fierobe, H.-P.; Mingardon, F.; Mechaly, A.; Bélaïch, A.; Rincon, M.; Pagès, S.; Lamed, R.; Tardif, C.; Bélaïch, J.-P.; Bayer, E. Action of Designer Cellulosomes on Homogeneous Versus Complex Substrates. J. Biol. Chem. 2005, 280, 16325-16334. [CrossRef] [PubMed]

7. Moraïs, S.; Morag, E.; Barak, Y.; Goldman, D.; Hadar, Y.; Lamed, R.; Shoham, Y.; Wilson, D.; Bayer, E. Deconstruction of Lignocellulose into Soluble Sugars by Native and Designer Cellulosomes. mBio 2012, 3, e00508-12. [CrossRef]

8. Davidi, L.; Moraïs, S.; Artzi, L.; Knop, D.; Hadar, Y.; Arfi, Y.; Bayer, E. Toward Combined Delignification and Saccharification of Wheat Straw by a Laccase-Containing Designer Cellulosome. Proc. Natl. Acad. Sci. USA 2016, 113, 10854-10859. [CrossRef] [PubMed]

9. Gunnoo, M.; Cazade, P.-A.; Galera-Prat, A.; Nash, M.; Czjzek, M.; Cieplak, M.; Alvarez, B.; Aguilar, M.; Karpol, A.; Gaub, H.; et al. Nanoscale Engineering of Designer Cellulosomes. Adv. Mater. 2016, 28, 5619-5647. [CrossRef] [PubMed]

10. Leis, B.; Held, C.; AndreeBen, B.; Liebl, W.; Graubner, S.; Schulte, L.-P.; Schwarz, W.; Zverlov, V. Optimizing the Composition of a Synthetic Cellulosome Complex for the Hydrolysis of Softwood Pulp: Identification of the Enzymatic Core Functions and Biochemical Complex Characterization. Biotechnol. Biofuels 2018, 11, 1-15. [CrossRef]

11. Fan, L.; Zhang, Z.; Yu, X.; Xue, Y.; Tan, T. Self-Surface Assembly of Cellulosomes with Two Miniscaffoldins on Saccharomyces Cerevisiae for Cellulosic Ethanol Production. Proc. Natl. Acad. Sci. USA 2012, 109, 13260-13265. [CrossRef]

12. Nataf, Y.; Bahari, L.; Kahel-Raifer, H.; Borovok, I.; Lamed, R.; Bayer, E.; Sonenshein, A.; Shoham, Y. Clostridium Thermocellum Cellulosomal Genes Are Regulated by Extracytoplasmic Polysaccharides via Alternative Sigma Factor. Proc. Natl. Acad. Sci. USA 2010, 107, 18646-18651. [CrossRef] [PubMed]

13. Leis, B.; Held, C.; Bergkemper, F.; Dennemarck, K.; Steinbauer, R.; Reiter, A.; Mechelke, M.; Moerch, M.; Graubner, S.; Liebl, W.; et al. Comparative Characterization of All Cellulosomal Cellulases from Clostridium Thermocellum Reveals High Diversity in Endoglucanase Product Formation Essential for Complex Activity. Biotechnol. Biofuels 2017, 10, 1-16. [CrossRef] [PubMed]

14. Lytle, B.; Myers, C.; Kruus, K.; Wu, J.-H. Interactions of the CelS Binding Ligand with Various Receptor Domains of the Clostridium Thermocellum Cellulosomal Scaffolding Protein, CipA. J. Bacteriol. 1996, 178, 1200-1203. [CrossRef]

15. Pagès, S.; Bélaïch, A.; Bélaïch, J.-P.; Morag, E.; Lamed, R.; Shoham, Y.; Bayer, E. Species-specificity of the Cohesin-dockerin Interaction between Clostridium Thermocellum and Clostridium Cellulolyticum: Prediction of Specificity Determinants of the Dockerin Domain. Proteins 1997, 29, 517-527. [CrossRef]

16. Moraïs, S.; Barak, Y.; Caspi, J.; Hadar, Y.; Lamed, R.; Shoham, Y.; Wilson, D.; Bayer, E. Cellulase-Xylanase Synergy in Designer Cellulosomes for Enhanced Degradation of a Complex Cellulosic Substrate. mBio 2010, 1, e0285-10. [CrossRef] [PubMed]

17. Kahn, A.; Moraïs, S.; Galanopoulou, A.; Chung, D.; Sarai, N.; Hengge, N.; Hatzinikolaou, D.; Himmel, M.; Bomble, Y.; Bayer, E. Creation of a Functional Hyperthermostable Designer Cellulosome. Biotechnol. Biofuels 2019, 12, 1-15. [CrossRef]

18. Gold, N.; Martin, V.J. Global View of the Clostridium Thermocellum Cellulosome Revealed by Quantitative Proteomic Analysis. J. Bacteriol. 2007, 189, 6787-6795. [CrossRef]

19. Dykstra, A.; Brice, L.; Rodriguez Jr, M.; Raman, B.; Izquierdo, J.; Cook, K.; Lynd, L.; Hettich, R. Development of a Multipoint Quantitation Method to Simultaneously Measure Enzymatic and Structural Components of the Clostridium Thermocellum Cellulosome Protein Complex. J. Proteome Res. 2014, 13, 692-701. [CrossRef]

20. Olson, D.; Tripathi, S.; Giannone, R.; Lo, J.; Caiazza, N.; Hogsett, D.; Hettich, R.; Guss, A.; Dubrovsky, G.; Lynd, L. Deletion of the Cel48S Cellulase from Clostridium Thermocellum. Proc. Natl. Acad. Sci. USA 2010, 107, 17727-17732. [CrossRef]

21. Liu, Y.-J.; Liu, S.; Dong, S.; Li, R.; Feng, Y.; Cui, Q. Determination of the Native Features of the Exoglucanase Cel48S from Clostridium Thermocellum. Biotechnol. Biofuels 2018, 11, 1-13. [CrossRef]

22. Chang, J.; Anandharaj, M.; Ho, C.; Tsuge, K.; Tsai, T.; Ke, H.; Lin, Y.; Ha-Tran, D.; Li, W.; Huang, C. Biomimetic Strategy for Constructing Clostridium Thermocellum Cellulosomal Operons in Bacillus Subtilis. Biotechnol. Biofuels 2018, 11, 1-13. [CrossRef]

23. Hirano, K.; Saito, T.; Shinoda, S.; Haruki, M.; Hirano, N. In Vitro Assembly and Cellulolytic Activity of a $\beta$-Glucosidase-Integrated Cellulosome Complex. FEMS Microbiol. Lett. 2019, 366, fnz209. [CrossRef] [PubMed]

24. Moraïs, S.; Stern, J.; Kahn, A.; Galanopoulou, A.; Yoav, S.; Shamshoum, M.; Smith, M.; Hatzinikolaou, D.; Arnold, F.; Bayer, E. Enhancement of Cellulosome-Mediated Deconstruction of Cellulose by Improving Enzyme Thermostability. Biotechnol. Biofuels 2016, 9, 1-12. [CrossRef] [PubMed] 
25. Song, H.-T.; Gao, Y.; Yang, Y.-M.; Xiao, W.-J.; Liu, S.-H.; Xia, W.-C.; Liu, Z.-L.; Yi, L.; Jiang, Z.-B. Synergistic Effect of Cellulase and Xylanase during Hydrolysis of Natural Lignocellulosic Substrates. Bioresour. Technol. 2016, 219, 710-715. [CrossRef] [PubMed]

26. Bajaj, P.; Mahajan, R. Cellulase and Xylanase Synergism in Industrial Biotechnology. Appl. Microbiol. Biotechnol. 2019, 103, 8711-8724. [CrossRef]

27. Huang, C.; Zhao, C.; Li, H.; Xiong, L.; Chen, X.; Luo, M.; Chen, X. Comparison of Different Pretreatments on the Synergistic Effect of Cellulase and Xylanase during the Enzymatic Hydrolysis of Sugarcane Bagasse. RSC Adv. 2018, 8, 30725-30731. [CrossRef]

28. Gonçalves, G.; Takasugi, Y.; Jia, L.; Mori, Y.; Noda, S.; Tanaka, T.; Ichinose, H.; Kamiya, N. Synergistic Effect and Application of Xylanases as Accessory Enzymes to Enhance the Hydrolysis of Pretreated Bagasse. Enzyme Microb. Technol. 2015, 72, 16-24. [CrossRef]

29. Moraïs, S.; Barak, Y.; Caspi, J.; Hadar, Y.; Lamed, R.; Shoham, Y.; Wilson, D.; Bayer, E. Contribution of a Xylan-Binding Module to the Degradation of a Complex Cellulosic Substrate by Designer Cellulosomes. Appl. Environ. Microbiol. 2010, 76, 3787-3796. [CrossRef]

30. del Pulgar, E.; Saadeddin, A. The Cellulolytic System of Thermobifida Fusca. Crit. Rev. Microbiol. 2014, 40, 236-247. [CrossRef]

31. Stern, J.; Kahn, A.; Vazana, Y.; Shamshoum, M.; Moraïs, S.; Lamed, R.; Bayer, E. Significance of Relative Position of Cellulases in Designer Cellulosomes for Optimized Cellulolysis. PLoS ONE 2015, 10, e0127326. [CrossRef]

32. Stern, J.; Moraïs, S.; Lamed, R.; Bayer, E. Adaptor Scaffoldins: An Original Strategy for Extended Designer Cellulosomes, Inspired from Nature. mBio 2016, 7, e00083-16. [CrossRef]

33. Arfi, Y.; Shamshoum, M.; Rogachev, I.; Peleg, Y.; Bayer, E. Integration of Bacterial Lytic Polysaccharide Monooxygenases into Designer Cellulosomes Promotes Enhanced Cellulose Degradation. Proc. Natl. Acad. Sci. USA 2014, 111, 9109-9114. [CrossRef] [PubMed]

34. Chen, C.-Y.; Lee, C.-C.; Chen, H.-S.; Yang, C.-H.; Wang, S.-P.; Wu, J.-H.; Meng, M. Modification of Lignin in Sugarcane Bagasse by a Monocopper Hydrogen Peroxide-Generating Oxidase from Thermobifida Fusca. Process Biochem. 2016, 51, 1486-1495. [CrossRef]

35. Gaber, Y.; Rashad, B.; Hussein, R.; Abdelgawad, M.; Ali, N.; Dishisha, T.; Várnai, A. Heterologous Expression of Lytic Polysaccharide Monooxygenases (LPMOs). Biotechnol. Adv. 2020, 43, 107583. [CrossRef]

36. Brenelli, L.; Squina, F.; Felby, C.; Cannella, D. Laccase-Derived Lignin Compounds Boost Cellulose Oxidative Enzymes AA9. Biotechnol. Biofuels 2018, 11, 1-12. [CrossRef] [PubMed]

37. Westereng, B.; Cannella, D.; Agger, J.; Jørgensen, H.; Andersen, M.; Eijsink, V.; Felby, C. Enzymatic Cellulose Oxidation Is Linked to Lignin by Long-Range Electron Transfer. Sci. Rep. 2015, 5, 1-9. [CrossRef] [PubMed]

38. Zhang, P.; Wang, B.; Xiao, Q.; Wu, S. A Kinetics Modeling Study on the Inhibition of Glucose on Cellulosome of Clostridium Thermocellum. Bioresour. Technol. 2015, 190, 36-43. [CrossRef] [PubMed]

39. Lamed, R.; Kenig, R.; Morag, E.; Calzada, J.; De Micheo, F.; Bayer, E. Efficient Cellulose Solubilization by a Combined Cellulosome Beta-Glucosidase System. Appl. Biochem. Biotechnol. 1991, 27, 173-183. [CrossRef]

40. Zhang, J.; Liu, S.; Li, R.; Hong, W.; Xiao, Y.; Feng, Y.; Cui, Q.; Liu, Y.-J. Efficient Whole-Cell-Catalyzing Cellulose Saccharification Using Engineered Clostridium Thermocellum. Biotechnol. Biofuels 2017, 10, 1-14. [CrossRef] [PubMed]

41. Yoav, S.; Stern, J.; Salama-Alber, O.; Frolow, F.; Anbar, M.; Karpol, A.; Hadar, Y.; Morag, E.; Bayer, E. Directed Evolution of Clostridium Thermocellum $\beta$-Glucosidase A Towards Enhanced Thermostability. Int. J. Mol. Sci. 2019, 20, 4701. [CrossRef] [PubMed]

42. Shinoda, S.; Kurosaki, M.; Kokuzawa, T.; Hirano, K.; Takano, H.; Ueda, K.; Haruki, M.; Hirano, N. Comparative Biochemical Analysis of Cellulosomes Isolated from Clostridium Clariflavum DSM 19732 and Clostridium Thermocellum ATCC 27405 Grown on Plant Biomass. Appl. Biochem. Biotechnol. 2019, 187, 994-1010. [CrossRef] [PubMed]

43. Gefen, G.; Anbar, M.; Morag, E.; Lamed, R.; Bayer, E. Enhanced Cellulose Degradation by Targeted Integration of a Cohesin-Fused $\beta$-Glucosidase into the Clostridium Thermocellum Cellulosome. Proc. Natl. Acad. Sci. USA 2012, 109, 10298-10303. [CrossRef]

44. Li, X.; Xiao, Y.; Feng, Y.; Li, B.; Li, W.; Cui, Q. The Spatial Proximity Effect of Beta-Glucosidase and Cellulosomes on Cellulose Degradation. Enzyme Microb. Technol. 2018, 115, 52-61. [CrossRef]

45. Waeonukul, R.; Kosugi, A.; Tachaapaikoon, C.; Pason, P.; Ratanakhanokchai, K.; Prawitwong, P.; Deng, L.; Saito, M.; Mori, Y. Efficient Saccharification of Ammonia Soaked Rice Straw by Combination of Clostridium Thermocellum Cellulosome and Thermoanaerobacter Brockii $\beta$-Glucosidase. Bioresour. Technol. 2012, 107, 352-357. [CrossRef]

46. Tang, H.; Wang, J.; Wang, S.; Shen, Y.; Petranovic, D.; Hou, J.; Bao, X. Efficient Yeast Surface-Display of Novel Complex Synthetic Cellulosomes. Microb. Cell Factories 2018, 17, 1-13. [CrossRef]

47. Qi, K.; Chen, C.; Yan, F.; Feng, Y.; Bayer, E.; Kosugi, A.; Cui, Q.; Liu, Y.-J. Coordinated $\beta$-Glucosidase Activity with the Cellulosome Is Effective for Enhanced Lignocellulose Saccharification. Bioresour. Technol. 2021, 337, 125441. [CrossRef]

48. Wu, B.; Zheng, S.; Pedroso, M.; Guddat, L.; Chang, S.; He, B.; Schenk, G. Processivity and Enzymatic Mechanism of a Multifunctional Family 5 Endoglucanase from Bacillus Subtilis BS- 5 with Potential Applications in the Saccharification of Cellulosic Substrates. Biotechnol. Biofuels 2018, 11, 1-15. [CrossRef]

49. Carvalho, A.; Dias, F.; Nagy, T.; Prates, J.; Proctor, M.; Smith, N.; Bayer, E.; Davies, G.; Ferreira, L.; Romão, M.; et al. Evidence for a Dual Binding Mode of Dockerin Modules to Cohesins. Proc. Natl. Acad. Sci. USA 2007, 104, 3089-3094. [CrossRef] [PubMed] 
50. Valbuena, A.; Oroz, J.; Hervás, R.; Vera, A.; Rodríguez, D.; Menéndez, M.; Sulkowska, J.; Cieplak, M.; Carrión-Vázquez, M. On the Remarkable Mechanostability of Scaffoldins and the Mechanical Clamp Motif. Proc. Natl. Acad. Sci. USA 2009, 106, 13791-13796. [CrossRef] [PubMed]

51. Galera-Prat, A.; Moraïs, S.; Vazana, Y.; Bayer, E.; Carrión-Vázquez, M. The Cohesin Module Is a Major Determinant of Cellulosome Mechanical Stability. J. Biol. Chem. 2018, 293, 7139-7147. [CrossRef] [PubMed]

52. Galera-Prat, A.; Vera, A.; Moraïs, S.; Vazana, Y.; Bayer, E.; Carrión-Vázquez, M. Impact of Scaffoldin Mechanostability on Cellulosomal Activity. Biomater. Sci. 2020, 8, 3601-3610. [CrossRef] [PubMed]

53. Hong, W.; Zhang, J.; Feng, Y.; Mohr, G.; Lambowitz, A.; Cui, G.-Z.; Liu, Y.-J.; Cui, Q. The Contribution of Cellulosomal Scaffoldins to Cellulose Hydrolysis by Clostridium Thermocellum Analyzed by Using Thermotargetrons. Biotechnol. Biofuels 2014, 7, 1-17. [CrossRef] [PubMed]

54. Vazana, Y.; Moraïs, S.; Barak, Y.; Lamed, R.; Bayer, E. Chapter 23: Designer Cellulosomes For Enhanced Hydrolysis of Cellulosic Substrates. In Cellulases; Gilbert, H., Ed.; Method in Enzymology; Elsevier Inc.: Amsterdam, The Netherlands, 2012; Volume 510, ISBN 978-0-12-415931-0.

55. Basen, M.; Rhaesa, A.; Kataeva, I.; Prybol, C.; Scott, I.; Poole, F.; Adams, M. Degradation of High Loads of Crystalline Cellulose and of Unpretreated Plant Biomass by the Thermophilic Bacterium Caldicellulosiruptor Bescii. Bioresour. Technol. 2014, 152, 384-392. [CrossRef] [PubMed]

56. Kataeva, I.; Foston, M.; Yang, S.-J.; Pattathil, S.; Biswal, A.; Pool, F., II; Basen, M.; Rhaesa, A.; Thomas, T.; Azadi, P.; et al. Carbohydrate and Lignin Are Simultaneously Solubilized from Unpretreated Switchgrass by Microbial Action at High Temperature. Energy Environ. Sci. 2013, 6, 2186-2195. [CrossRef]

57. Young, J.; Chung, D.; Bomble, Y.; Himmel, M.; Westpheling, J. Deletion of Caldicellulosiruptor Bescii CelA Reveals Its Crucial Role in the Deconstruction of Lignocellulosic Biomass. Biotechnol. Biofuels 2014, 7, 1-8. [CrossRef]

58. Brunecky, R.; Chung, D.; Sarai, N.; Hengge, N.; Russell, J.; Young, J.; Mittal, A.; Pason, P.; Wall, T.; Michener, W.; et al. High Activity CAZyme Cassette for Improving Biomass Degradation in Thermophiles. Biotechnol. Biofuels 2018, 11, 1-12. [CrossRef] [PubMed]

59. Caspi, J.; Barak, Y.; Haimovitz, R.; Irwin, D.; Lamed, R.; Wilson, D.; Bayer, E. Effect of Linker Length and Dockerin Position on Conversion of a Thermobifida Fusca Endoglucanase to the Cellulosomal Mode. Appl. Environ. Microbiol. 2009, 75, 7335-7342. [CrossRef]

60. Vazana, Y.; Moraïs, S.; Barak, Y.; Lamed, R.; Bayer, E. Interplay between Clostridium Thermocellum Family 48 and Family 9 Cellulases in Cellulosomal versus Noncellulosomal States. Appl. Environ. Microbiol. 2010, 76, 3236-3243. [CrossRef]

61. Kahn, A.; Moraïs, S.; Chung, D.; Sarai, N.; Hengge, N.; Kahn, A.; Himmel, M.; Bayer, E.; Bomble, Y. Glycosylation of Hyperthermostable Designer Cellulosome Components Yields Enhanced Stability and Cellulose Hydrolysis. FEBS J. 2020, 287, 4370-4388. [CrossRef]

62. Lambertz, C.; Garvey, M.; Klinger, J.; Heesel, D.; Klose, H.; Fischer, R.; Commandeur, U. Challenges and Advances in the Heterologous Expression of Cellulolytic Enzymes: A Review. Biotechnol. Biofuels 2014, 7, 1-15. [CrossRef]

63. Cui, W.; Han, L.; Suo, F.; Liu, Z.; Zhou, L.; Zhou, Z. Exploitation of Bacillus Subtilis as a Robust Workhorse for Production of Heterologous Proteins and Beyond. World J. Microbiol. Biotechnol. 2018, 34, 1-19. [CrossRef]

64. Nishizaki, T.; Tsuge, K.; Itaya, M.; Doi, N.; Yanagawa, H. Metabolic Engineering of Carotenoid Biosynthesis in Escherichia Coli by Ordered Gene Assembly in Bacillus Subtilis. Appl. Environ. Microbiol. 2007, 73, 1355-1361. [CrossRef] [PubMed]

65. Tsuge, K.; Matsui, K.; Itaya, M. One Step Assembly of Multiple DNA Fragments with a Designed Order and Orientation in Bacillus Subtilis Plasmid. Nucleic Acids Res. 2003, 31, e133. [CrossRef] [PubMed]

66. Liang, Y.; Ang, E.; Zhao, H. Engineered Pentafunctional Minicellulosome for Simultaneous Saccharification and Ethanol Fermentation in Saccharomyces Cerevisiae. Appl. Environ. Microbiol. 2014, 80, 6677-6684. [CrossRef]

67. Karbalaei, M.; Rezaee, S.; Farsiani, H. Pichia Pastoris: A Highly Successful Expression System for Optimal Synthesis of Heterologous Proteins. J. Cell. Physiol. 2020, 235, 5867-5881. [CrossRef] [PubMed]

68. Dong, C.; Wang, X.; Sun, W.; Chen, L.; Li, S.; Wu, K.; Ma, L.; Liu, Y. Engineering Pichia Pastoris with Surface-Display Minicellulosomes for Carboxymethyl Cellulose Hydrolysis and Ethanol Production. Biotechnol. Biofuels 2020, 13, 1-9. [CrossRef] [PubMed]

69. Vassylyeva, M.; Klyuyev, S.; Vassylyev, A.; Wesson, H.; Zhang, Z.; Renfrow, M.; Wang, H.; Higgins, N.; Chow, L.; Vassylyev, D. Efficient, Ultra-High-Affinity Chromatography in a One-Step Purification of Complex Proteins. Proc. Natl. Acad. Sci. USA 2017, 114, 5138-5147. [CrossRef]

70. Hirano, K.; Nihei, S.; Hasegawa, H.; Haruki, M.; Hirano, N. Stoichiometric Assembly of the Cellulosome Generates Maximum Synergy for the Degradation of Crystalline Cellulose, as Revealed by In Vitro Reconstitution of the Clostridium Thermocellum Cellulosome. Appl. Environ. Microbiol. 2015, 81, 4756-4766. [CrossRef]

71. Ha-Tran, D.; Lai, R.-Y.; Nguyen, T.; Huang, E.; Lo, S.-C.; Huang, C. Construction of Engineered RuBisCO Kluyveromyces Marxianus for a Dual Microbial Bioethanol Production System. PLoS ONE 2021, 16, e0247135. [CrossRef]

72. Andreu, C.; del Olmo, M. Whole-Cell Biocatalysis in Seawater: New Halotolerant Yeast Strains for the Regio- and Stereoselectivity Reduction of 1-Phenylpropane-1,2-Dione in Saline-Rich Media. ChemBioChem 2020, 21, 1621-1628. [CrossRef] [PubMed] 
73. Anandharaj, M.; Lin, Y.-J.; Rani, R.; Nadendla, E.; Ho, M.-C.; Huang, C.; Cheng, J.-F.; Chang, J.-J.; Li, W.-H. Constructing a Yeast to Express the Largest Cellulosome Complex on the Cell Surface. Proc. Natl. Acad. Sci. USA 2020, 117, 2385-2394. [CrossRef] [PubMed]

74. Olson, D.; Giannone, R.; Hettich, R.; Lynd, L. Role of the CipA Scaffoldin Protein in Cellulose Solubilization, as Determined by Targeted Gene Deletion and Complementation in Clostridium Thermocellum. J. Bacteriol. 2013, 195, 733-739. [CrossRef] [PubMed] 